\title{
La pregunta por el quién del ser-con: Heidegger en su Ser y Tiempo ${ }^{1}$
}

\author{
Juan José Garrido Periñán²
}

Recibido: 07 de septiembre de 2017 / Aceptado: 18 de julio de 2018

Resumen: Se trata de pensar y abrir el horizonte del ser-con desde los análisis fenomenológicos vertidos por Heidegger en la I Sección de su libro Ser y Tiempo (§§ 25-27), respetando y aceptando sus propias limitaciones intrínsecas y a pesar del carácter aparentemente negativo que rodea a este existenciario, a fin de radicalizarlo, extenderlo y ubicarlo en su posibilidad más genuina. Por esta razón, a través de una interpretación de corte fenomenológico, se ha querido potenciar los posibles rendimientos de un ser-con en propiedad, enfatizando la necesidad de interpretar el opus magnum heideggeriano desde el horizonte de la mismidad del Dasein. La conclusión apunta sobre dos vías temáticas, a saber: a) a tomar la mismidad del Dasein, por cuanto constituye una posibilidad ejecutiva de existir conforme a lo que este ente es, en tanto condición necesaria y suficiente para pensar un ser-con en propiedad; b) a establecer, casi a modo de esbozo, una relación entre ser-con, libertad y mismidad, la cual tiene su base temática en una presumible igualdad de orden pre-ontológico.

Palabras clave: mismidad; ser-con; fenomenología; temporalidad; Heidegger.

\section{[en] The question for the who of being-with: Heidegger in his Being and Time}

\begin{abstract}
In order to radicalize, extend and locate in its most genuine possibility the existential word being-with, this Paper tries to think and open its horizon from phenomenological analyzes developed by Heidegger I Section of the Book Being and Time ( $\S \S 25-27)$, respecting and accepting its own and intrinsic limitations and despite the seemingly negative character that surrounds this existential. For this reason, through a phenomenological interpretation, it has been tried to enhance the possible yields of a being-with-property. To this end, the emphasis has been placed on the need to interpret the Heideggerian opus magnum from the horizon of the Selfhood of Dasein. In order to think a beingwith-property the conclusion of this Paper would like to point out two routes: a) to take the Selfhood of Dasein as necessary and sufficient condition to think a being-with-property, being that the Selfhood of Dasein constitutes an executive possibility of existing where this entity is what it is; $b$ ) to establishes a relationship between being-with, freedom and Selfhood in the which has its thematic foundation in a presumed equality of pre-ontological order.
\end{abstract}

Key words: selfhood; being-with; phenomenology; temporality; Heidegger.

Sumario: 1. Introducción: el compromiso fenomenológico para el desvelamiento del horizonte del ser-con. 2. La impronta metodológica de la fenomenología: el horizonte del ser-con y la existencia. 2.1.

1 Este trabajo se ha realizado bajo la cobertura del siguiente Proyecto I+D De Excelencia: “Dinámicas del cuidado y lo inquietante. Figuras de lo inquietante en el debate fenomenológico contemporáneo y las posibilidades de una orientación filosófica. Configuración teórica y metodológica" (FFI2017/83770-P), proporcionado por el Ministerio de Innovación, Ciencias y Universidades del Reino de España.

$2 \quad$ Universidad de Sevilla jjgarper@us.es ORCID: 0000-0002-7586-7579 
El rescate del ámbito del ser-con desde el método fenomenológico-hermenéutico. 2.2. Dasein como existencia, no como Vorhandensein. 3. Desvelamiento de la mismidad del Dasein: hacia la pregunta por el quién. 3.1. La pregunta por el quién del Dasein. 4. El desvelamiento del ser-con: co-existencia y solicitud. 4.1. De la co-existencia a la solicitud. 4.2. Del ser-con impropio al ser-con propio: preparación del camino. 5. Fundamentación del ser-con propio: modificación (apropiación), ser-junto-al-ente, verdad de la existencia y ser-libre. 5.1. El carácter de la modificación. 5.2. La apertura del ser-dentro-de y la irrupción del ser-con: ser-libre y la mismidad. 5.3. La verdad de la existencia y la posibilidad de un ser-con propio: la libertad para/del otro; 6 . Referencias bibliográficas.

Cómo citar: Garrido Periñán, J.J. (2019): "La pregunta por el quién del ser-con: Heidegger en su Ser y Tiempo", en Revista Anales del Seminario de Historia de la Filosofia 36 (1), 175-200.

\title{
1. Introducción: el compromiso fenomenológico para el desvelamiento del horizonte del ser-con
}

\begin{abstract}
¿Será posible al menos rastrear y preparar la pregunta sobre la "mismidad"3 [Selbstheit] del Dasein, desde el momento estructural de la aparición de los otros, y dentro del análisis existencial llevado a cabo por Heidegger en el marco de la I Sección ( $\S \S 25-27)$ de su tratado Ser y Tiempo $?^{4}$ Y, entre tanto, tal tentativa, ¿es posible ejercerla respetando el modo de aparecer de los otros, dentro de la esfera común "ser-con" [Mit-sein], tal y como aparece en la obra, integrando sus propias limitaciones y deficiencias de la definición dada por el mismo Heidegger? ${ }^{5}$
\end{abstract}

3 El sí-mismo, o la mismidad, apunta a un fenómeno temporal en las dimensiones prácticas del "mundo entorno" [Um-Welt], "mundo compartido" [Mit-Welt] y, por último, "mundo de sí mismo" [Selbst-Welt] (Cfr. Heidegger, M. Einführung in die phänomenologische Forschung. II. Abteilung, Band 17, Frankfurt a. M.: Vittorio Klostermann, 2006, p. 176; Phänomenologie des Religiösen Lebens. II. Abteilung, Band 60, Frankfurt a. M.: Vittorio Klostermann. 1995, pp. 11, 13, 103, 187-188, 192, 204, 211, 212-214, 227-228, 228, 232, 237-241, 245247, 253-255, 298, 331-332; Platon: Sophistes. II. Abteilung, Band 19, Frankfurt a. M.: Vittorio Klostermann, 1992, pp. 54-58, 54-58, 342, 348, 440-441, 442; Ontologie: Hermeneutik der Factizität. II Abteilung, Band 63, Frankfurt a. M.: Vittorio Klostermann, 1988, pp. 29 y 102; Wegmarken. Gesamtausgabe, I. Abteilung, Band 9, Frankfurt a. M.: Vittorio Klostermann, 1976, pp. 236, 338-344, 344-347 y Der Grundprobleme der Phänomenologie. II Abteilung, Band 24, Frankfurt a. M.: Vittorio Klostermann, 1975, pp. 194, 224- 228, 242 , 249, 394-395 422, 425). No hay que olvidar que la analítica existencial, propedéutica para alcanzar el horizonte de aprehensión de la "Temporalidad del ser" [Temporalität des Seins], pasaba, si y solo si, por un análisis de las estructuras existenciales del ente que se pregunta por el ser, el Dasein.

$4 \quad$ Nota bene, a pesar de que pudiera resultar interesante esbozar un despliegue temático y relacional entre el modo de abordaje de la noción "mismidad" en Ser y Tiempo y la corriente denominada "hermenéutica de sí", ejercida con protagonismo, entre otros, por el filósofo francés P. Riccoeur (Soi-même comme un autre, París: Seuil, 1990), o el por el también francés M. Foucault (L’Herméneutique du Sujet, Paris: Gallimard, 2001), nuestro artículo de investigación se abstendrá de emprender semejante tentativa, pues lo importante es, para nosotros, más bien, vislumbrar el rol metódico y temático que la noción mismidad tiene dentro de los $\S \S 25-27$ de la obra magna heideggeriana y, por ende, el presente articulo de investigación supone un esfuerzo de concentración analítica sobre el existenciario ser-con, entreviendo sus fallas, deficiencias y posibles vinculaciones con el fenómeno fundante de la mismidad.

5 Obviamente esta pregunta no sale de la nada, sino que es una continuación de las meditaciones ejercidas por el autor de este texto en pos de abrir fenomenológicamente el ámbito de la experiencia del sí-mismo en la obra Ser y Tiempo. Como prueba de ello, con anterioridad a esta meditación, se intentó dejar preparada la pregunta por la mismidad desde el existenciario "mundo" [Welt] ("Caminos y esbozos para una apertura fenomenológica del horizonte mismidad desde la constitución ontológica del mundo en Ser y Tiempo" [Aceptado para su publicación], en: TRANS/FORM/AÇAO: Revista de Filosofia 42) y desde la irrupción de la mundaneidad del ente intramundano, en su carácter sumamente espacial ("Horizontes fenomenológicos de la espacialidad en Ser y Tiempo: la relevancia del ser-en como vía de acceso a la mismidad del Dasein", en: Eidos: Revista de Filosofía de la Universidad del Norte 29, 2018, pp. 150-174). Se recomienda acudir, al menos, a estos 2 artículos, a fin de 
Nuestra meditación está comprometida metodológicamente, esto es, busca atenerse al método filosófico denominado "fenomenología", por la sencilla razón, y a nuestro juicio, de que es la fenomenología, en tanto corriente y modus vivendi del pensamiento, una manera óptima, eximia, de hacerse cargo del modo a partir del cual es posible todo venir a presencia de las cosas, los entes. ¿Qué es lo que queremos transparentar aquí? La esfera del "mundo compartido" [Mit-Welt], o sea, responder a la pregunta que intenta desvelar cómo aparece en el ser humano la tendencia a vivir conforme a los demás, dentro de una comunidad, un pueblo, o en el discurrir público de las opiniones, como forma de "habladurías" [Gerede], etc. La enfatización que pone Heidegger, en su asunción del método fenomenológico de origen husserliano, es plural y extensa, con sus dimes y diretes, pero lo importante es que, para Heidegger, la fenomenología, por decirlo así, en su motivación más interna, carece de un compromiso para con la quiddidad, desde la manera en la que se intenta lograr una determinación sobre qué-son las cosas; más bien, lo importante, para una fenomenología comprometida con un pathos existencial, es desvelar el modo, el "cómo" [Wie], los fenómenos y las cosas aparecen. Heidegger denomina a este uso metodológico, derivado de la fenomenología husserliana, antes de Ser y Tiempo, con el nombre de "indicación formal" [formale Anzeige]. La fenomenología, para resumir, no consiste, tan solo, en erigirse en una actitud respetuosa para con lo que se $\mathrm{da}$, o aparece, sino que intenta desentrañar las condiciones formales-trascendentales que hacen posible todo aparecer. De lo que se va a tratar aquí no es sobre un ente que tiene la forma relativa al "objeto" [Gegenstand], en virtud del cual se pueda determinar lo que-es, sino de un fenómeno que, noles volens, queda intrínsecamente ligado a lo que somos, en tanto emparentado a unas "maneras de existir" [Weisen $z u$ existieren], las cuales quedan remitidas a un sentido a priori por el momento ignoto ${ }^{8}$. Los "existenciarios" [Existenzialen], que actúan en calidad de indicadores formales: Um-; Mit-; Selbst-, y, en general, todos los existenciarios vertidos en el opus

poder comprender la línea de continuidad de la investigación desarrollada. Todas las traducciones al español de la obra de Heidegger vertidas en este texto de investigación son de nuestra responsabilidad.

6 La indicación formal hace mención de las referencias hermenéuticas, indicativas-ejecutivas, que surcan la existencia. No son nexos normativos, sino formales, modos de ser, al igual que los existenciarios. Más aún, la indicación formal, en la obra del joven Heidegger, son como un prefacio para con los existenciarios $(C f r$. Phänomenologie des Religiösen Lebens. op. cit., p. 16).

7 Gegenstand es unas de las traducciones al español de objeto, el cual puede ser traducido, del mismo modo, por Objekt. Desde diferentes perspectivas, hay quienes sostienen su tajante división (Caygill, H. A Kant dictionary. Oxford-Massachusetts: Blackwell, 2000, p. 317), considerándola importantísima para la matriz filosófica de la filosofía trascendental kantiana, siendo Gegenstände objetos de la experiencia en su sentido lato, mientras que Objekt es el objeto de la experiencia en un sentido restringido, o sea, como objeto relativo al entendimiento. Ahora bien, hay controversia, Pedro Ribas, uno de los traductores al español de Kritik der reinen Vernunft (Kant, I. Crítica de la razón pura. Taurus, Madrid: 2005, pp. XXV), según parece, desestima la diferenciación, al pensarla de poco importante; también lo hacen Förster y Rosen (Kant, I. Opus postumun. New York: Cambridge University Press, 1993, p. 49), traductores al inglés del Opus Postumun kantiano. Heidegger, a mi parecer, a lo largo de su interpretación, mantiene tal división, entendida en términos ontológicos, en virtud, precisamente, del aporte que lo trascendental tendría sobre la misma experiencia, haciéndola depender de criterios logicistas, es decir, pensado el objeto como Objekt, o correlato lógico de la unidad de apercepción, en presunto divorcio con la intuición sensible, a la que estaría, irremediablemente, emparentada la noción germana Gegenstand.

8 Este elemento "apriórico" es mentado por Heidegger en tanto horizonte "pre-teorético" [Vor-theoretische]. La estructura de "previedad": "haber-previo" [Vor-habe], "ver-previo" [Vor-sicht] y "pre- concepción" [Vorgriff], fue desarrollado especialmente en el curso de 1923 (Ontologie: Hermeneutik der Factizität., op. cit.). La dilucidación de esta estructura previa es el objetivo final de toda hermenéutica de la facticidad y constituye la base temática de la noción de sentido tan importante en Ser y Tiempo. 
magnum heideggeriano, siempre van a ser pensados, ligados a la propia idiosincrasia existencial y hermenéutica del ente que se pregunta por el ser del ente: el Dasein. Esta es la apuesta que realizó, para bien o para mal $^{9}$, el propio Heidegger en su obra Ser y Tiempo, y que nosotros acogemos, apelando a su importancia metodológica, porque pensamos que es una forma sobresaliente de hacer resplandecer la valía fenomenológica del horizonte de la mismidad, la cual, según nuestra tesis, nuclea y pivota todos los análisis explicitados en el tratado de 1927, pero que, al mismo tiempo, queda como soterrada, quizás por la excesiva importancia que tiene el horizonte de la temporalidad del $\operatorname{ser}^{10}$, en su despliegue histórico, como "olvido del ser" [Vergessenheit des Seins], de una tradición, la metafísica, que ha permitido su exclusión apelando al ente en sus diversas manifestaciones: eidos, ousia, cogito, yo, etc.

La pregunta por la mismidad del Dasein, en su constatación como experiencia de sí, no es la pregunta sobre el qué, ni tan siquiera por el cómo, sino sobre el "quién" [Wer]. En este sentido, responder a la pregunta quiénes somos nosotros mismos mientras hablamos, comemos, leemos, nos relacionamos con los demás, etc., es el objetivo prioritario para con este articulo de investigación. De suerte que el objetivo antes mentado constituya un objetivo necesario, pero no suficiente, pues, como se verá más adelante, la pregunta sobre el nosotros conllevará la dilucidación de la esfera de la mismidad ${ }^{12}$.

9 Empleamos la expresión "para bien o para mal" señalando el vasto recorrido de la obra de Heidegger, en sus formulaciones sobre "el giro" [Die Kehre]. La bibliografía acerca de la Kehre es inmensa (Cfr. Hermann, F-W. Wege ins Ereignis: zu Heideggers Beiträgen zur Philosophie. Frankfurt a. M.: Vittorio Klostermann, 1994, pp. 65-84; Fräntzki, E. Die Kehre. Heideggers Schrift Vom Wesen der Wahrheit: Urfassungen und Druckfassungen. Pfaffenweiler: Centaurus-Verlagsgesellschaft, 1985; Rosales, A., "Zum Problem der Kehre im Denken Heideggers", en: Zeitschrift für philosophische Forschung 38, 1984, pp. 241-262; y Richardson, W-J. Heidegger: Through Phenomenology to Thought. The Hague: Martinus Nijhoff, 1963, pp. 212-262), pero hay una cierta unanimidad sobre su definición entre los investigadores más reputados. Nosotros pensamos que Kehre refleja el intento llevado a cabo por parte de Heidegger de pensar la relevancia fenomenológica del ser allende la analítica existencial, en su sustitución por una tarea "des-subjetivizadora", que entiende el ser como un fenómeno histórico-epocal, según el cual, el Dasein no es sujeto activo en el esclarecimiento del sentido del ser, sino, antes bien, pasivo, pues debe recoger lo que se da históricamente, el envío de su "época" [Epoché]. No es de extrañar, por tanto, que el lenguaje empleado por Heidegger, después de lo que hemos llamado Kehre, raye con el dictum poético: la tarea consistía en decir lo in-decible, aquello para lo que no estamos preparados históricamente. Hölderlin y los primeros griegos. Para un desarrollo más extenso, véase nuestro artículo ("Carta sobre el Humanismo: consideraciones del "ahi" del ser. ¿Es posible habitar el claro del ser? en: Eikasia: Revista Internacional de Filosofia 61, 2015, pp. 302-320).

10 Justamente aquí va a radicar, en esencia, el hilo conductor del artículo de investigación, o sea, en el planteo según el cual es posible una lectura, con base fenomenológica, de Ser y Tiempo, en tanto fenomenología de la mismidad, donde tal fenómeno juega un rol constitutivo dentro de la tarea, para Heidegger provisoria, de la analítica del Dasein. Este planteamiento, por tanto, supone la no consideración de las propias motivaciones de Heidegger, el cual tenía en mente una meta mayor, por cuanto el objetivo era sacar de su olvido el sentido a partir del cual se pudiera dar cuenta de la experiencia ontológica denominada ser.

11 Muy esclarecedor resulta el Curso del Semestre de verano de 1934, el cual queda transcrito por los apuntes de Helena Weiss, sobre las diferencias ontológicas-existenciales que se encuentran en la modalidad del preguntar sobre el qué -Wasfrage- y sobre el quién -Werfrage- (Cfr. Logik als die Frage nach dem der Sprache. II. Abteilung, Band 38, Frankfurt a. M.: Vittorio Klostermann, 1998, p. 33-35).

12 Cfr. infra., 5.; .5.1; 5.2., y 5.3 . 


\section{La impronta metodológica de la fenomenología: el horizonte del ser-con y la existencia}

Es bien sabido que Ser y Tiempo no constituye un tratado cuyo propósito sea la elaboración de una suerte de fenomenología del nosotros, de la inter-subjetividad, pero ello no quiere decir que lo que realza el problema de la intersubjetividad, la constitución del nosotros, entendido ontológicamente, no haya sido pensado, y abierto, en tal obra ${ }^{13}$. El primer atisbo del nosotros, traducido a la manera de Heidegger por el modo de aparición del "mundo compartido" [Mit-Welt], sale a luz en la I Sección de Ser y Tiempo (§ 25), justo cuando se producen los análisis fenomenológicos del modo en que el ente intramundano se constituye. Por esta razón, y ante un primer vistazo general, las consideraciones que podamos realizar acerca de la esfera del ser-con serán negativas, pues los aspectos intrínsecos a tal esfera, como son el hablar en común, las opiniones o la sociabilidad en general, aparecen revestidos bajo adjetivaciones poco favorables y negativas: "autoenajenación" [Selbstentäusserung], "pérdida de sí" [Selbstverlorenheit] o "auto-encubrimiento"14 [Selbstverdeckung]. Por si esto fuera poco, desde un aspecto netamente metódico, el "otro", en tanto dimensión ontológica que constituye el nosotros, vendría a fundamentarse en calidad de excusa y mero preámbulo superfluo, a fin de aprehender lo esencial: la verdad que transparenta el "ser-para(vuelto-a)-la-muerte" [sein-zum-Tode], en tanto posibilidad eminente que conecta al Dasein, singularizándolo, con su genuina e "irrespectiva" [unbezüglich] temporalidad existencial-Zeitlichkeit-. Los fenómenos analizados en la II Sección tales como "el llamado" [der Ruf], "el llamado de la conciencia" [der Ruf des Gewissens] o la "resolución" [Entschlossenheit], además de adquirir un cariz individual muy notorio - diríamos, rayano en la heroicidad del que se la juega a vivir o morir-, por cuanto sus consecuencias radican en romper y quebrar los mecanismos hermenéuticos del mundo, -precisamente aquellos que ligan al Dasein en un mundo y posibilitan su pertenencia a un entorno [Um-]-, revelan que Heidegger pensó la "propiedad" [Eigentlichkeit] de la existencia en términos altamente trágicos y desestabilizadores, esbozando una situación en la que el Dasein, el ente que "le va su ser en ser(existir)" [es geht ihm um sein Sein], para ser "lo que es", se ve obligado a tomar unas decisiones radicales e incomunicables para con otro. Desde esta conjunción, de fuerte marcado individual y "decisionista", de demolición de cualquier estructura de pertenencia hermenéutica, de ligazón con el mundo, resulta arduo pensar que todavía haya algún espacio para realzar fenomenológicamente la esfera del ser-con en Ser y Tiempo.

Una vez expuestas las líneas generales en la que se adjetiva la esfera del mundo compartido, es menester acudir al rescate de la fenomenología vertida en el libro, o sea, es hora de ser consecuentes con la propia metodología llevada a cabo por Heidegger: una fenomenología-hermenéutica ${ }^{15}$. A continuación, comprenderemos cómo, si de verdad respondemos con rigor al método fenomenológico, la importancia de la esfera de los otros y el mundo compartido será trascendental.

\footnotetext{
13 A lo largo del texto se va a emplear, diversamente, los términos "ser-con", "nosotros" e incluso "intersubjetividad", para abordar y pensar el mismo problema: cómo se da fenomenológicamente lo que Heidegger denomina ontoexistencialmente "ser-con" [Mit-sein].

14 Cfr. Sein und Zeit. Tübingen: Max Niemeyer, 2006, pp. 126-130.

15 A fin de obtener unas líneas generales, claras y precisas, de lo que significa este término, recomendamos la lectura de: Rodríguez, R. La transformación hermenéutica de la fenomenología: una interpretación de la obra de Heidegger. Madrid: Tecnos, 1997.
} 


\subsection{El rescate del ámbito del ser-con desde el método fenomenológico- hermenéutico}

Heidegger sabe muy bien que el "sentido del ser" [Sinn von Sein], el cual siempre aparece ligado a una "tonalidad afectiva" [Stimmung], en el modo de la "cuestionabilidad" [Fraglichkeit], se ha extraviado, aunque no perdido del todo ${ }^{16}$. De ahí que el meollo de la cuestión consista en abrir un horizonte de aprehensibilidad del venir a presencia del ente mismo. La fenomenología constituye aquí la posibilidad que lleva a cabo tal apertura del venir a la presencia ${ }^{17}$, preocupándose por dilucidar el modo de acceso de tal venir a presencia, soterrado por la actitud "teorética"18 [Theoretische], y presupuesto implícitamente en la actitud natural y cotidiana, a-temática. Por tanto, de lo que se trata con la fenomenología, según Heidegger, es de traer plenamente al ámbito de la mostración lo que en la actitud cotidiana era tácito, pero no explícito, de modo "precedente y concomitante"19 [vorgängig und mitgängig]: el ser mismo. Esto significa, además, que el ser mismo está ya dado de antemano, que la esfera del ser-con, al igual que sucede con el ser, está ya dada $\mathrm{y}$, por tanto, de alguna manera, de lo que se trataría es de lograr una apertura del horizonte de su comprensibilidad. El aspecto de ya dado, lo ya-sido, del "haberllegado-a-ser" 20 [Gewordensein], es muy importante para realzar una actitud que solo la fenomenología es capaz de pensar: no se trata de abrir un nuevo y originario horizonte de comprensibilidad, sino de radicalizar una actitud que ya está dada de antemano, materializada en el modo en que nosotros, a diario, nos comportamos. Con la dimensión del ser-con, por ende, en analogía con lo que sucede con el problema del ser, se trata de tematizar, hacer explícito, lo abierto por él mismo, pero, también, dilucidar los "presupuestos" [Voraussetzungen] en el que queda inserto. De descubrir lo alienado en lo presupuesto se encargará la hermenéutica, pensada por Heidegger como una propedéutica fenomenológica cuyo cometido es ponernos en el correcto punto de acceso de la apertura fenomenológica.

Pues bien, afirmar que la esfera del ser-con no está fabulada ni inventada por Heidegger, cual recurso filosófico cuyo omnímodo objetivo es preparar la pregunta por el ser, o que la esfera del ser-con no es algo que haya que pasarse de largo a causa

16 Es una consecuencia metódica, y casi de sentido común, apelar a que el olvido del ser nunca ha de realizarse plenamente, sino que éste ha de quedar tácito en los diversos comportamientos del ser humano, ora cuando se habla sobre el partido de fútbol que se ha visto, ora cuando se dialoga sobre cualquier tema que concierne a la vida diaria. No olvidemos que, aparte de ser el "más lejano" [am fernsten] y el "más cercano" [am nächsten], el ser del Dasein, su sentido, es "no-extraño" [nicht fremd]. (Cfr. Sein und Zeit, op. cit., p. 16).

17 Convendría no olvidar lo que dice Heidegger: "La ontología solo es posible como fenomenología" [Ontotogie ist nur als Phänomenologie möglich] (Ibíd., p. 35).

18 Desde 1919, Heidegger piensa que la filosofía se ejerce dentro de un dominio "pre-teorético" [Vor-theoretische], en cuanto actividad que intenta aprehender la experiencia inmediata de la vida, y que queda conformada como "ciencia originaria de la vida" [Urwissenschaft des Lebens]. Por tanto, la filosofía, siendo pre-teorética, tiene como finalidad poner al descubierto las estructuras ontológicas de la vida fáctica, distinguiéndose, en su actividad, de actitudes teoréticas, basadas en la objetivación y la reflexión, como de una actitud de corte práctico, basada exclusivamente en la acción.

19 Cfr. Sein und Zeit, op. cit., p. 31.

20 La importancia del fenómeno del "haber-llegado-a-ser", en la constitución de la facticidad, es abordada por Heidegger por primera vez en 1920, en relación con las Epístolas Paulinas, desde la experiencia kairológica del kerygma apostólico. Tal importancia es analizada en el curso de 1920/21: Introducción a la Fenomenología de la Religión (Cfr. Phänomenologie des religiösen Lebens, op. cit., pp. 3-159). Hemos trabajado la cuestión (Cfr. "La experiencia de la religiosidad: caminos fenomenológicos en busca de la mismidad del Dasein. Heidegger y la fenomenología de la religión”, en: Revista Portuguesa de Filosofía 73, 2017, pp. 533-556). 
de su poca importancia, resulta factible entenderlo mientras sea posible atender al rigor expuesto por el recurso metodológico, el cual nos dice que no ha sido posible, al menos para Heidegger, mentar el problema del ser-con si éste no ha sido ya de antemano constituido, o dado, como modo de ser del Dasein, altamente ligado a su forma cotidiana de ser. Por tanto, el problema que trasluce el ser-con, hasta ahora ignoto, va a configurar, no solo las posibilidades de éxito de cara a preparar la pregunta que recupere el sentido del ser, sino aquello que constituye lo más característico del Dasein: su mismidad.

Las adjetivaciones ya mentadas ${ }^{21}$, que enfatizaban el carácter negativo de la esfera compartida, constituyen un análisis que se queda corto con el mismo proceder llevado a cabo por Heidegger en su incesante lucha por desentrañar el sentido general y trascendental del ser del ente. Entonces, ¿por qué debemos conformarnos con las características negativas que, prima facie, aparecen en el libro Ser y Tiempo? ¿Acaso su radicalización no es una consecuencia directa con el mismo método filosófico empleado por Heidegger: la fenomenología? ¿No es este empeño, ejercido en esta meditación, coherente con el método empleado por Heidegger?

\subsection{Dasein como existencia, no como Vorhandensein}

Se puede decir, sin miedo a equivocarse, que, desde prácticamente 1919, en la conversión que hace Heidegger de la fenomenología de su maestro Husserl, el sentido primordial de todo fenómeno es el "sentido de ejecución"22 [Vollzugssinn]. Que sea el sentido de ejecución el valedor de toda fenomenalidad ha de entenderse como una advertencia: la vivencia, que la fenomenología pretende rescatar, a través del utillaje de la epojé y la reducción, es algo que, de primeras, no debe ser pensado ni reflexionado, sino vivido en su nuda inmediatez ${ }^{23}$. Los fenómenos están, además de referenciados Hermenéuticamente en el mundo, en una constante "movilidad"24 [Bewegung]. No basta con aprehenderlos, hay que vivirlos, ejecutarlos, "en cada

21 Cfr. supra., nota 13.

22 Heidegger propone que las posibilidades de acceso al fenómeno estén marcadas bajo 3 sentidos: "sentido de contenido" [Gehaltsinn], "sentido de relación" [Bezugssinn] y "sentido de ejecución" [Vollzugssin], siendo el sentido de contenido subsidiario del sentido relacional, esto es, de la forma cómo la existencia es vivida, bajo sus referencias y situaciones concretas y fácticas. El sentido de ejecución es importante aquí porque no hay ningún sentido relacional que no conlleve, desde sí mismo, una ejecución, una praxis, un hacer. Los contenidos que, como indicadores formales, expresa la hermenéutica de la facticidad, deben ser, en "cada caso" [jeweiligkeit] ejecutados, llevados a praxis. Esta división, en la manera de entender el fenómeno, no es nueva de $\operatorname{Ser} y$ Tiempo, sino que ya fue tematizada, al menos implícitamente en algunos cursos docentes anteriores a 1927 (Cfr. Prolegomena zur Geschichte des Zeitbegriffs. II. Abteilung, Band 20, Frankfurt a. M.: Vittorio Klostermann, 1979, pp. 194 ss.).

23 Cfr. supra., nota 17.

24 En términos muy latos, Heidegger entiende la existencia cinéticamente. Por lo general, la movilidad característica de la existencia humana es hermenéutica, sobre todo movida por el "estado de caída" [Verfallen]. El análisis de Heidegger, por el contrario, no queda ahí, sino que analiza toda una serie de "categorías de movimiento" [Bewegungskategorien] de la vida fáctica (Sein und Zeit, op. cit., §.12, pp. 55 s., y §. 38, pp. 175 s; Phänomenologische Interpretationen zu Aristoteles. Einführung in die phänomenologische Forschung. II. Abteilung, Band 61, Frankfurt a. M.: Vittorio Klostermann, 1985, pp. 117-130 y 131-151; Phänomenologische Interpretation ausgewählter Abhandlungen des Aristoteles zu Ontologie und Logik. Gesamtausgabe, II. Abteilung, Band 62, Frankfurt a. M.: Vittorio Klostermann, 2005, pp. 354 ss.). Para completar la interpretación, se recomienda la lectura de: Kisiel, Th. The Genesis of Heidegger Being and Time. California: University of California Press, 1995, pp. 257 ss., y Segura Peraita, C. Hermenéutica de la vida humana. En torno al Informe Natorp de Martin Heidegger. Madrid: Trotta, 2002, pp.146 ss.). 
caso" [Jeweiligkeit]. Precisamente, en virtud del imperativo ejecutivo que mueve toda fenomenalidad, en el acceso al Dasein, en su peculiar modo de ser basado en la existencialidad, se da una asimetría. El Dasein en su saberse, para con la conquista de su punto de acceso, se muestra como un ente esquivo para consigo mismo. La disparidad adviene porque lo que se le abre, en la modalidad de la inmediatez de su cotidianidad, en el plano -si se quiere así- "óntico", dista de lo que éste ha de conservar en su comprensión pre-ontológica, primero, y en su comprensión ontológica, después. La vía del acceso al Dasein comienza si y solo si desde el modo en que éste se comporta desde su día a día, tensado por su propia facticidad, historicidad y cultura; pero, al mismo tiempo, tal familiaridad producida por los mecanismos de pertenencia al mundo, tiene que convivir, habitar, con un distanciamiento que es esencial e irrenunciable: el Dasein no es un ente que "está-ahí"25 [Vorhandensein], sino que su modo de ser radica en la existencia, en la modalidad del "tener-que-ser" [zu-sein] y el "ser-en cada-caso-mío"26 [Jemeinigkeit]. La complejidad del acceso al Dasein, en su desvelamiento fenomenológico, no radica tan solo en su tendencia a constituirse cual reflejo del mundo que habita ${ }^{27}$, más bien es una consecuencia sintomática de la propia constitución existencial del Dasein, a caballo entre el modo respectivo del ente intramundano y el modo ontológico que vertebra una existencia movida por su tendencia a la cuestionabilidad.

Ahora bien, ¿qué tiene que ver lo dicho con los objetivos marcados en la meditación, los cuales tenían en mente trasparentar fenomenológicamente el ámbito comunitario del ser-con? En nuestra opinión, las advertencias metodológicas llevadas a cabo nos sitúan en un punto extremadamente importante, en relación con la cuestión de la mismidad, como hemos dicho ya previamente sobre la dilucidación de la estructura del "nosotros"28: el carácter de sí mismo de este ente existencial llamado Dasein, para su conceptualización, no puede consistir en el desarrollo de una ontología propia de la Vorhandenheit. Por esta razón, cuando mentamos la expresión "mismidad", no podemos auxiliarnos en lo legado por la tradición filosófica, pues el Dasein no es -tan solo- un cogito, un yo o un sujeto-trascendental, etc. Heidegger lucha furibundamente contra lo que él piensa que es una tendencia humana ${ }^{29}$ hacia su propia "auto-cosificación" 30 [Selbstverdinglichung]. Concepciones tales

25 Vorhandensein se contrapone al modo de ser del Dasein, basado en la existencia, en cuanto "estado de arrojado" [Geworfenheit], que sostiene la propia asunción de su temporalidad, un modo de ser basado en la "cuestionabilidad" de su propio ser. La existencia pertenece al Dasein; el "estar-ahí" a los entes ya dados, en "estado de efectivo" [Wirklichkeit], en la realidad. Por tanto, los entes que no son Dasein, los entes intramundanos, no existen, pues no preguntan sobre sí mismos, no se comportan, asumiéndose, desde un horizonte temporal.

26 Cfr. infra., 3.

27 Sein und Zeit, op. cit., pp. 15-16: "En el Dasein mismo y, con ello, en su comprensión de ser reside lo que vamos a poner de manifiesto como la refracción ontológica de la comprensión del mundo sobre la interpretación del Dasein" [Im Dasein selbst und damit in seinem eigenen Seinsverständnis liegt das, was wir als die ontologische Rückstrahlung des Weltverständnisses auf die Daseins-auslegung aufweisen werden].

28 Cfr. supra., nota 10.

29 En resumidas cuentas, el ser humano es pensado en la obra Ser y Tiempo como oportunidad proyectiva y lugar comprensor de aquello que es, se da, el ser.

30 Por supuesto que esta lucha se personificó en su distanciamiento, sobre todo, de la fenomenología egológica husserliana. Por motivos de extensión, no podemos demorarnos en las similitudes/diferencias de los pensamientos de Husserl y Heidegger (Cfr. Merker, B. Selbsttäuschung und Selbsterkenntnis. Zu Heideggers Transformation der Phänomenologie Husserls. Frankfurt a. M.: Suhrkamp Verlag, 1988; Hermann, F-W. Hermeneutik und Reflexion. Der Begriff der Phänomenologie des seinsgeschichtlichen Denkens. Frankfurt a. M.: Vittorio Klostermann, 2000; Blust, F-K. Selbstheit und Zeitlichkeit. Heideggers neuer Denkansatz Seinsbestimmung des Ich, Würzburg, Königshausen \& Neumann, 1987 y Overenget, E. Seeing the Self. Heidegger on Subjectivity. 
como la "substancialización" del alma-Seelensubstanz-, aquellas que abogan por la importancia de la conciencia -Dinglichkeit des Bewußtsein-o, por último, las concepciones de origen cristiano sobre el concepto de persona-Gegenstädlichkeit der Person- naufragan, son insuficientes, si la tarea principal es realzar, a fin de obtenerlo, el carácter peculiar del ente que se pregunta por el ser, que siente, padece y piensa: el Dasein.

Al socaire de las advertencias metodológicas ejercidas hasta este momento, nos ponemos en camino de, primeramente, pensar de modo recto la cuestión de la mismidad, en relación con los existenciarios "tener-que-ser" [zu-sein] y "ser-encada-caso-mío" [Jemeinigkeit]. A partir de entonces, en segundo lugar, plantearemos la problemática del ser-con. Pero tenemos que ir con pies de plomo, paso a paso.

\section{Desvelamiento de la mismidad del Dasein: hacia la pregunta por el quién}

La mayoría de las veces, en la definición otorgada a la noción de Dasein, se emplea en demasía el carácter relativo al orden existencial. La apelación a la existencia, además de ser usual, corre el riesgo de caer en la más absoluta banalización, hasta el punto de poder confundir las pretensiones de Heidegger con la corriente existencialista $^{31}$. Para Heidegger, el carácter existencial que porta el Dasein se ve recogido en los existenciarios: "tener-que-ser" y "ser-en-cada-caso-mío". "Existencialidad" significa portar la marca que implica el hecho fáctico de "tenerque-ser", en este mundo, y que las referencias ejecutivas, implícitas en el hecho de ser, se vuelvan contra nosotros (mí), imprecándonos, forzándonos a tener que decidir, en unas decisiones en la que nuestro (mi) propio ser queda en juego. Si esto es cierto, aunque explicado brevemente, y las posibilidades del "tener-que-ser" señalen ante mi propio ser (existir), las cuales se materializan en la toma de decisiones que envuelven al ser del Dasein, consideramos pertinente, pues, enfatizar que, desde la propia existencialidad, aun en su grado más nimio y cotidiano, las referencias hacia la "propiedad" [Eigenlichkeit] e "impropiedad" [Uneigenlichkeit] son ya manifiestas en tanto vías en las que el Dasein, desde sus posibilidades existenciales, puede ser sí mismo. Ser sí mismo significa, para nosotros, ser capaz de generar decisiones conformes a la propiedad del existir. Se podrá ahora entender la distancia que media entre Husserl y Heidegger sobre el problema de la "autodonación"32 [Selbstgebung], no en exclusividad apelando al gusto husserliano por Descartes, sino porque Heidegger piensa que la reflexión no es un mecanismo válido para el rescate de la experiencia de la mismidad ${ }^{33}$.

Estas advertencias, por lo demás, van a cobrar su importancia a razón de su capacidad preventiva: para versar pertinentemente sobre los "otros", no es suficiente

Dordrecht-Boston-London: Springer, 1998, pp. 139-165).

31 Una de las más sobresalientes respuestas ante tal acusación ( $C f$ r. "Brief über den Humanismus", op. cit., pp. 313-364).

32 Cfr. Sein und Zeit, op. cit., p. 115 y Grundprobleme der Phänomenologie, op. cit., pp. 219-251.

33 Heidegger, M. Logik als die Frage nach dem der Sprache, op. cit., p. 4: “¡Debemos actuar, salir por fin de la reflexión!" [Wir sollen ins Handeln, aus der Reflexion heraus!]. Para un desarrollo de la cuestión, en relación con la concepción del sí-mismo, recomiendo la lectura de: Blust, F-K. Selbstheit und Zeitlichkeit. Heideggers neuer Denkansatz zur Seinsbestimmung des Ich, op. cit., pp. 66 ss., y Rodríguez, R. Del sujeto y la verdad. Madrid: Síntesis, 2015, pp. 61-82. 
la argumentación que apela a teorías tipo "empatía" [Einfühlung], en las que el yo corre la suerte de ser un "otro-yo", igual, clonado, permeable para con la experiencia del otro ${ }^{34}$. Esta crítica no es ejercida por Heidegger por considerarla ajena a sus intereses filosóficos, sino, más bien, porque, desde el ejemplo de la teoría de la empatía, la experiencia del otro queda transfigurada desde sus cimientos, al no partir de un modo recto de aprehender la experiencia de la mismidad, jamás impregnada bajo la signatura de la Vorhandenheit.

Llegados a este punto, creemos, que se puede comprender porqué tuvimos que comenzar este artículo de investigación, a través de las páginas precedentes, recurriendo a cuestiones metódicas, con la consigna de realzar el modo de acceso de la mismidad del Dasein. La creencia que las referencias de nuestro propio ser, nuestro yo, servirán a fin de poder dar cuenta de la experiencia y vivencia del otro, es un error capital que Heidegger no está dispuesto a aceptar ${ }^{35}$. Entonces, podríamos preguntar: ¿qué es lo que está dispuesto a aceptar Heidegger, en este punto de la meditación, sobre el acceso de los otros? Estimamos que el punto de partida de Heidegger consiste en afirmar que, originariamente, en virtud de la atenencia al propio modo de darse de este fenómeno de los "otros", lo primero con que nos topamos es con una dimensión indiferente, en la que no es posible realizar semejanzas ni desemejanzas entre el "yo", el "tú" o el "nosotros"36. Nota bene, indiferenciación no significa ignorancia o desconocimiento, sino, más bien, impotencia de atender al modo de acceso del fenómeno de la mismidad ${ }^{37}$. Si carecemos, según Heidegger, de un conocimiento explícito y temático sobre nuestra mismidad, ¿cómo es posible que versemos fenomenológicamente sobre la experiencia del otro, de la comunidad o incluso de la alteridad? ¿No es esto un despropósito? La respuesta señala a la demora del pensar, e indica que, para comprender la experiencia del "ser-con" [Mit-sein] y de la "co-existencia" [Mit-Dasein], es menester partir de la propia estructura del ser del Dasein. O sea, desde el uso de otras palabras: no puede darse una experiencia de la mismidad, si antes no se ha integrado la experiencia de los otros, porque el Dasein no es un ser dispuesto en una atalaya, indiferente al mundo y a sus semejantes, sino que es un ente en relación ${ }^{38}$, co-originario a la dimensión abierta por el ser-con.

${ }^{34}$ Cfr. Sein und Zeit, op. cit., pp. 124 ss. Tampoco sería válida, para Heidegger, la teoría husserliana de la intersubjetividad expuesta en la Quinta Meditación de Meditaciones Cartesianas (Cartesianische Meditationen und Pariser Vorträge. Husserliana I. Den Haag: Martinus Nijhoff, 1973, pp. 121-184). Para un desarrollo de la cuestión se recomienda atender a la lectura de: Theunissen, M. Der Andere. Studien zur Socialontologie der Gegenwart. Berlin-New York: Walter de Gruyter \& Co, 1964, pp. 156-186.

35 Cfr. Sein und Zeit, op. cit., pp. 124 ss.

36 Cfr. Ibid., p. 116.

37 Cfr. infra., 4.; 4.1.; 4.2.

38 Hemos desarrollado una fenomenología del ser-en, ora acercándonos al tema de la "corporalidad" [Leiblichkeit], ora, desde criterios metodológicos a la hora de interpretar la obra Ser y Tiempo, en las siguientes meditaciones ("Fenomenología del ser-en: ciencia originaria de la vida y hábitat del Dasein. En búsqueda de la vivencia inmediata de la vida", en: Revista da Faculdade de Letras da Universidade do Porto 33, 2017, pp. 139-160 y "Ser-en-el-cuerpo: tentativas para un esclarecimiento sobre cómo aparece un cuerpo. En y mundo", en: Daimon: Revista Internacional de Filosofia. Suplemento 5, 2017, pp. 63-73). Conviene, empero, destacar que el "seren" [In-sein], como experiencia fenomenológico-existencial, no ha de mentar el quedar "junto-a/dentro-de" [bei] algo (Cfr. Sein und Zeit, op. cit., pp.123-125). En definitiva, si el Dasein, en su mostración como ente señalado por la comprensión del ser, no ha de ser ni un yo, ni una substancia, ni cualquier otra modalidad de "carácter cósico" [Dinghaftigkeit], esto implica que el Dasein, de partida, se constituye como un horizonte co-originario con lo que siempre ya se relaciona, dentro del mundo-entorno y mundo-compartido. ¿Por qué, entonces, demandar una unidad, si este ente es cooriginario a sus relatas? Aquí sale a relucir la cuestión de la mismidad y su encaje en la sistematicidad inherente a Ser y Tiempo. 


\subsection{La pregunta por el quién del Dasein}

La pregunta por el ser común, el ser-con, esto es, aquello que la intersubjetividad deja abierto, es pensado por Heidegger a través del horizonte que cuestiona sobre el "quién" [Wer]. Como sabemos, desde Ser y Tiempo, la respuesta a esta pregunta -quién es el Dasein- es unilateral: "el uno" ${ }^{39}$ [das Man]. Lo que ocurre es que, en virtud de su estructura pública, no debemos entender el existenciario das Man como algo sumamente negativo, sino en tanto horizonte marcado por la indiferencia que nos encontramos cuando dilucidamos sobre la cuestión: quiénes somos nosotros mismos $^{40}$. La inclinación que pone en liza la pregunta por el quién tiene una característica que la hace única: cuando preguntamos por el quién estamos dirigiendo nuestra atención, no solo a lo abierto desde lo preguntado, sino a lo relacionado mismo, nuestro propio ser. El quién se dirige radical y lacerantemente hacia lo que somos, interrogando al ente que hace preguntas: el Dasein. Tal es así que, si somos honestos para con nosotros mismos, ante la pregunta: ¿quiénes somos?, de primeras, no tenemos una respuesta fehacientemente válida, completa, rigurosa. La mayoría de las veces nos vemos obligados a considerar cuestiones pasadas, a afirmar una identidad del yo, a la manera kantiana ${ }^{41}$. Heidegger es consciente de la debilidad de las respuestas empleadas en la afirmación advenida por la pregunta por el quién, pues sabe muy bien que ninguna categoría, producto de lo que él denomina metafísica, va a recoger, en integridad, el ser del Dasein. Pero que piense tal que así, ya nos debería dar, al menos, una indicación que guie nuestras pesquisas. Creemos no equivocarnos al manifestar, si de verdad el objetivo principal de la meditación consiste en transparentar la estructura del ser-con, la necesidad de buscar, rastrear y radicalizar el horizonte de la mismidad del Dasein, pues por mismidad, prima facie, entendemos la disposición existencial en la que el Dasein, en cada caso, es conforme a lo que "es" (existencia). Ahora bien, pareciera que nuestra meditación ha caído en un círculo vicioso, ya que se resguarda en el carácter de la mismidad, pero, al mismo tiempo, manifiesta que de la mismidad no se puede formular un "concepto" [Begriff]. Entonces, ¿qué hacemos? ¿nos contentamos con la imposibilidad, la debacle, la impotencia? Aunque parezca inverosímil y sorpresivo en parte, la respuesta se encuentra en la radicalización de la estructura del uno. El planteo que hace Heidegger al respecto resulta muy meridiano para alumbrar nuestros intereses:

39 Ibíd., p. 271: "Perdido en la opinión pública del uno y en su habladuría, el Dasein, al escuchar al uno-mismo, pasa por alto su propio sí-mismo" [Sich verlierend in die Öffentlichkeit des Man und sein Gerede überhört es im Hören auf das Man-selbst das eigene Selbst].

40 Cfr. Heidegger, M. Logik als die Frage nach dem der Sprache, op. cit., p. 33-35.

41 Estamos pensando en la apercepción trascendental kantiana (Cfr. Kant, I. Kritik der reinen Vernunft, B 135, Hamburg, Felix Meiner Verlag, 1956 y Heidegger, M. Kant und das Probleme der Metaphysil. Abteilung, Band 3, Frankfurt a. M.: Vittorio Klostermann, 1991, pp. 13-19, 65-85, 171-203 y 249- 312). Como resalta Alejandro Vigo ("La atestiguación, en el modo de ser del Dasein, de un poder-ser propio y en estado de resuelto", en: R. Rodríguez (ed.), Ser y Tiempo de Martin Heidegger. Un comentario fenomenológico, Tecnos: Madrid, 2016, pp. 167-218), en su comentario a Ser y Tiempo, la conciencia que intenta esbozar temáticamente Heidegger, en su análisis, presenta rasgos similares al delineamiento de la conciencia kantiana (Kant, I., Metaphysische Anfangsgründe der Tugendlehre, Metaphysik der Sitten, Zweiter Teil, Hamburg, Felix Meiner Verlag, 2017, pp. 32 ss.), dentro de unos límites, pues la conciencia, presentada por Heidegger, es refractaria para su incardinación en horizontes normativos y/o morales. Pero es, precisamente, esta intolerancia de la conciencia para con su unívoca conformación en mecanismos morales y objetivos, lo que une las concepciones kantianas y heideggerianas, ya que, para ambos pensadores, la conciencia es siempre ya una conciencia de sí, la cual es pensada como una manera esencialmente ejecutiva, práctica. 
se ha de partir, por rigor fenomenológico, del modo en el que diariamente estamos, desde la "cotidianidad del término medio" [durchschnittliche Alltäglichkeit], con el fin de, una vez ejercido una mirada fenomenológica-existencial sobre lo que somos cuando somos el uno, -es decir, nadie-, re-obtener la posibilidad, cual conquista, de un sí-mismo propio, que sirva para orientar rectamente el modo de aparición de los otros. La necesidad de comenzar el análisis por la cotidianidad del término medio no es azarosa ni volitiva, responde a una exigencia de orden formal que tiene que ver con la fenomenología, pues no es posible partir de "pre-suposiciones" [Voraussetzungen] ideales, sino de aquello que "se da" [es gibt]. Por esta razón, comenzar desde el modo en el que nos comportamos diariamente sirve para arrancar de los fenómenos "atestiguaciones" [Bezeugungen], esto es, propias experiencias de sí que tiene que ver con lo que vivimos diariamente.

Por otro lado, resulta al menos curioso que el camino solo sea de ida, y no de vuelta, a saber, no es posible partir de una experiencia propia del sí-mismo, de la mismidad, si antes no se ha comenzado desde la atestiguación por la que somos desde lo despejado por la estructura del uno. Fenómenos como "pérdida de sí" o "uniformidad anímica y niveladora" constituyen las atestiguaciones mediante las cuales Heidegger comienza sus análisis en torno a la pregunta por el quién. Esto servirá para empezar a pensar que la experiencia de la mismidad, para el Dasein, consiste en un estado de "modificación" [Verwandlung] de la vivencia extendida por el uno.

No es posible dar la vuelta al camino, esto es, partir de una experiencia propia para, desde ahí, modificar la impropiedad del estado producido por la cotidianidad del término medio. Es hora, pues, de pensar con más detenimiento la estructura del "ser-con" [Mit-sein].

\section{El desvelamiento del ser-con: co-existencia y solicitud}

Lo que desvela el "ser-con" [Mit-sein] es algo muy serio, constituyéndose, en tanto existenciario, como una estructura formal de carácter ontológico, esto es, fundamental, que sirve para explicar cualquier modalidad de determinación y manifestación comunal, relacional con respecto a los otros, cualquier forma de convivencia $^{42}$. La radicalidad de la tendencia comunal, propia del ser-con, es para el Dasein importantísima, hasta el punto de que podemos decir, sin riesgo a errar, que el Dasein, ora en el modo de la "ocupación" [Besorgen], ora en el modo de la cotidianidad, cuando está dentro-del mundo, el otro está siempre pre-figurado para con él mismo, no siendo posible, para su captación fenomenológica, desligar el ámbito del otro de lo que el Dasein mismo es ${ }^{43}$.

Otro Dasein es siempre "ya ahí con" [ist mit da] el propio Dasein ${ }^{44}$. La señalización que pone en relación el modo de aparecer de los otros con el mundo-entorno no es baladí. En primera instancia, tal relación, no significa que los otros se den en el mundo bajo la modalidad del estar-ahí "ante los ojos" [vorhandene Persondinge],

\footnotetext{
42 Cfr. Sein und Zeit, op. cit., pp. 117-126.

43 Que el otro se encuentra ya implícito en la experiencia del entorno queda claro en el análisis del útil (Cfr. Ibid., pp. 63-113).

$44 \quad$ Cfr. Ibid., p. 118.
} 
más bien, siguiendo el hilo conductor de las investigaciones heideggerianas, los otros aparecen revestidos, como implícitos, en la relación ocupacional-práctica que el Dasein tiene con los entes intramundanos. Encontramos la huella de los otros, a saber, cuando empleamos el martillo para ajustar el mobiliario, o cuando usamos el teléfono móvil de nuestro amigo, también cuando acudimos al rastro y vemos, observamos, "cosas" de segunda mano $^{45}$. Esta experiencia que, para la intuición general, es de fácil captación, sirve para orientarnos sobre la radicalidad de la experiencia del otro-en-el-Dasein, mas no para ponernos cara a cara con ella. La experiencia del otro, para Heidegger, desborda los mecanismos de rastreo que, desde la ocupación-práctica, el Dasein pueda tener, intuyendo que, tras la elaboración, por ejemplo, del martillo, si es artesanal, está implícito el mundo del artesano. Pero ¿por qué? Hay que pensar que tanto Um- como Mit- son co-originarios. Si bien, grosso modo, la estructura del entorno quedaba fundamentada en un contexto global, holístico, de carácter hermenéutico ${ }^{46}$, el horizonte comunal, perteneciente al ser-con, aparecía, siempre ya, en el mismo hecho del "habla"47 [Rede]. El martillo, además de ser enlazado en un respectivo "para-que" $[U m-z u]$, era pensado, a la par, como una forma "por-mor-de" [Worum-willen], es decir, como un elemento integral y en consonancia con el modo de ser del Dasein, un elemento que se integraba al contexto hermenéutico, de sentido ${ }^{48}$, que soporta el Dasein en su calidad intransferible de "ser-en-el-mundo" [in-der-Welt-sein]. Por tanto, co-existir no es una plusvalía que debiera desarrollarse a posteriori del trato ocupacional, el cual domina nuestra actividad diaria en el mundo, sino que, su aparecer, se da con la misma intensidad, y en igualdad de condiciones, que tal estructura del mundo-entorno. Sucede, entonces, que la estructura ontológica del ser-con se encuentra soterrada por una experiencia fenoménica que tiene un nombre claro en la obra de Heidegger: la "co-existencia" 49 [Mit-dasein]. Es conveniente no confundir la estructura ontológica del ser-con con la estructura óntica de la co-existencia. Lo veremos.

45 Cfr. Moreno, C., "Una suerte de calma hechizada. Praxis de extrañamiento y trascendencia poética (Paseando por el rastro con Gómez de la Serna), en: Contrastes: Revista Internacional de Filosofía 21, 2016, pp. 74-94.

46 Los análisis sobre la mundaneidad, en general, y del útil, en particular, son muy prolijos, por lo que baste esta explicación muy somera: la "totalidad respeccional" es un fenómeno ligado al "por-mor-de" [Worumwillen] respectivo al Dasein, o sea, al ámbito de auto-remisión que todo útil, en tanto para-algo, comporta. El existenciario del cual es deudor la "totalidad respeccional” es el "todo respeccional” [Bezugsganze], que vendría a actuar de elemento trascendental, por cuanto contendría la "totalidad-respeccional" [Bewandtnisganzheit] cuanto sus (auto)referencias hacia el Dasein -la significatividad y la mundaneidad-.

47 Siguiendo a Aristóteles, Heidegger analiza los modos doxáticos del ser-uno-con-otros, rehabilitando el concepto de polis y la definición de zoon logon politikon. Curioso lo que dice el mismo Heidegger en su traducción del zoon logon echon: "El hombre es un viviente que lee el periódico" [Der Mensch ist ein Lebendes, das Zeitung liest] (Grundbegriffe der aristotelischen Philosophie, II. Abteilung, Band 18, Frankfurt a. M: Vittorio Klostermann, 2002, p. 108). Para nosotros, estas indicaciones recobran valor porque, ya en el mismo hecho de hablar, la esfera de la co-existencia se impone, pues, en este sentido, si doxa es "tener un parecer sobre algo" que aparece, o ha aparecido, el habla indica que el tener un parecer siempre es dicho para con otro que, por así decir, recoge lo dicho. La convivencia se comprendería, pues, como una forma de comunidad de los "pareceres", al modo en el que se desarrolla, por ejemplo, los diálogos platónicos, en los que un determinado grupo de personajes dialogan en torno a un parecer. Por tanto, el habla no solo prefigura el ámbito de la presencia del otro, sino que es deudora de tal estructura mentada aquí bajo el rótulo de "ser-con".

48 Reiteramos: al mentar la expresión sentido se quiere significar, a la par, el horizonte de previedad desde donde el Dasein, siendo en el mundo, abre los propios respectos que conforma los útiles en sus "para-algo" [Um-zu].

49 Cfr. Sein und Zeit, op. cit., p. 121. 


\subsection{De la co-existencia a la solicitud}

En el plano de la captación fenomenológica se vivencia, en primer lugar, la coexistencia, en tanto es el modo en el que nosotros, diariamente, hablamos, conversamos, preguntamos al compañero de trabajo cómo le fue su fiesta de cumpleaños, etc. La co-existencia es una modalidad de ser-en-el-mundo perteneciente al carácter existencial del Dasein y posibilitada porque el Dasein, esencialmente, es un sercomunitario, fundado en el ser-con. El hecho de que Heidegger, una vez explicitada la estructura del mundo-entorno, se vea obligado a demorarse, aunque dentro de las propias limitaciones de su análisis, a pensar el carácter comunitario que envuelve al Dasein, no es algo que deberíamos pasar por alto. Esta señalización indica, al menos, que el modo de comparecencia de los otros se ve implicado algo especial, diferente al de los útiles. Esta experiencia de distinción es bastante clara: el otro, que es otro Dasein, no se nos da como útil. El otro Dasein, aunque sea en el modo nivelado de la co-existencia, no puede ser reemplazado, sustituido o reparado. Además de todo esto, el otro revela al Dasein, poniéndolo en franquía, la propia estructura capital que estamos analizando aquí: la mismidad. Y no es que, conociendo el modo de comparecencia del otro, podamos obtener un conocimiento de nosotros mismos, antes bien, desde el otro los caracteres que, según Heidegger, desvelan la integridad del Dasein se hacen más patentes. ¿No es verdad que el otro, a pesar de tratarlo, a través del filtro de la cotidianidad como cadáver o "extinto" 50 [Verstorbene], nos pondría en franquía, en pos de pensar nuestra propia mortalidad? El pensamiento de la mortalidad no es accidental para Heidegger, pues pensar la mortalidad significa la posibilidad de aprehender el carácter temporal del Dasein, o sea, la Zeitlichkeit.

Después de lo dicho, ¿no estamos apelando a una suerte de teoría de la empatía para manifestar cierta preeminencia de la experiencia de los otros sobre el mundoentorno? No es así, ya que, medianamente, el modo de acceso para con los otros, que Heidegger llama "solicitud" [Fürsorge], es sumamente deficiente. La solicitud no es más que una indicación del fundamental rol que juega el ser-con para con el Dasein; la solicitud es la forma existencial-ontológica que patentiza y regula cualquier modo de relación humana para con el otro. De este modo, la atención, el cuidar-de, la indiferencia, el rechazo, la intolerancia, etc., son formas, propias e impropias, de responder a esta ontológica necesidad existencial que tiene el Dasein en calidad de ser-con. Que la solicitud quede soterrada no es un hecho nuevo que Heidegger hubiera pensado en $1927^{51}$.

Desde este horizonte, Heidegger reitera la importancia de pensar que, desde un estado de plena convivencia y cotidianidad, la experiencia fenomenológica no nos pone ante la conciencia de un yo, sino con "el sí-mismo cotidiano" 52 [das alltägliche Selbstsein], es decir, no con una cierta individualidad personal, que nos sirva para tomar distancia de los otros, sino con un horizonte sumido en el anonimato,

50 Justamente, cuando se realiza el análisis fenomenológico del morir, valga decir: sobre el ser-para(vuelto-a)-lamuerte" [sein-zum-Tode], cuyos resultados son relevantes para con el Dasein y la posibilidad de un existir en propiedad, Heidegger bifurca la experiencia de la muerte de los otros, la cual es siempre impropia y deficiente, y la muerte nuestra (mía), que es intransferible, insuperable e "irrespectiva" (Cfr. Sein und Zeit, op. cit., pp. 236267).

51 Al menos desde 1920, Heidegger ya se percata de las modalidades insuficientes de atender a la solicitud radical que forma el ser del Dasein (Cfr. Phenomenologie des Religiösen Lebens, op. cit.).

52 Cfr. Sein und Zeit,op. cit., pp. 126-130. 
infructuoso en relación con la tarea "identitaria" 53 , que tiene como objeto el ser como todos, esto es, como nadie ${ }^{54}$. Ahora bien, ser-nadie, como mínimo común múltiplo de nuestro estado cotidiano de ser, no significa una suerte de nihilismo al modo como Camus esbozó su Extranjero. Si se nos permite decirlo así, para Heidegger, palabras como anonimato y nadie significan exceso de pertenencia hermenéutica mundana, o sea, sobrecarga de tradición, historia, identidad. Se puede visualizar mejor en el ejemplo del individuo que, por sus razones históricas y culturales, para con toda pregunta, tiene una respuesta: "no hay mal que por bien no venga", "morir es el fin de la vida", "España es el mejor país del mundo", etc. Estas formulaciones, mentadas por la hermenéutica como pre-juicios, son ambivalentes en la obra heideggeriana, pues, por un lado, son fenómenos positivos, en la medida en que abren un horizonte de comprensión para el Dasein, pero, por otro, sumamente negativos, porque impiden al Dasein toparse con la constitución ontológica de su ser. En relación con la solicitud, el Dasein, cuando es nadie, se comporta, también, en el modo de la solicitud que interviene por el otro, bajo el carácter de sustitutivo [einspringend-beherrschende Fürsorge]. Esto tiene unas consecuencias muy graves, no solo en el terreno ético y político -a saber, de este modo funcionan las dictaduras-, sino porque le arrebata al Dasein la posibilidad de experimentar su propia temporalidad desde la implicación ontológica que tiene el otro ${ }^{55}$. El otro, desde esta forma impropia de solicitud, se retira como otro, queda abortado en su constitución ontológica.

Por otro lado, el acceso íntegro al otro no es fácil y esto lo muestra la definición de solicitud-propia dada por Heidegger, en cuanto se la piensa como una "solicitud anticipativo-liberadora" 56 [vorspringend-befriende Fürsorge], en virtud de la cual el Dasein, en una acción que se anticipa al estado de ruina proporcionado por la actitud cotidiana, basada en el nadie y el uno, logra reintegrar al otro-Dasein, devolverle su propia temporalidad. Por eso, dice Heidegger que, a través de la solicitud propia, se "devuelve el cuidado como cuidado" 57 [Rückgabe der Sorge als Sorge].

La importancia que le hemos dado a los diversos modos de acceso al otro, mentados con el título de solicitud, buscaba poner el acento en el camino que hace posible un recto acceso a la constitución comunal del Dasein explicitada con la signatura ser-con. Ahora sí que podemos afirmar que, desde el modo de ser de la solicitud propia, es posible pensar ontológicamente el genuino ser-con, o, con otras palabras: el radical "nosotros" [Wir] que constituye el ser del Dasein. Solo cuando dejamos

53 Esta consideración sobre la identidad se ubica dentro de la crítica que hace Heidegger al ideal filosófico que piensa en la "conciencia" [Bewußtsein] como principio rector del mundo. Esta crítica, que no podemos explicitar aquí, se extiende, diríamos, en su integridad, al movimiento del idealismo alemán. Expresiones tales como: ego, ego cogito, Egoismus, Egoität, Ich, Ichheit, Ichlich, etc., son usuales en la obra de Heidegger, precisamente, desde un tono altamente crítico, como expresiones equívocas de raíz, alejadas del modo de acceso de la mismidad del Dasein (Cfr. Heidegger, M. Einführung in die phänomenologische Forschung, op. cit., p. 240; Prolegomena zur Geschichte des Zeitbbegriffs, op. cit., pp. 131, 172, 326 y 341; Logik. Die Frage nach der Wahrheit, II. Abteilung, Band 21, Frankfurt a. M.: Vittorio Klostermann, 1976, p. 227; Geschichte der Philosophie von Thomas von Aquin bis Kant, II. Abteilung, Band 23, Frankfurt a. M.: Vittorio Klostermann, 2006, p. 236; Die Grundprobleme der Phänomenologie, op. cit., pp. 177, 182-185, 201 y 206-209). Baste estas referencias, aunque se pueden encontrar más en la vasta obra de Heidegger.

54 Cfr. supra., nota 38.

55 Creo que resulta obvia la afirmación a tenor de lo dicho: no ha de existir un conocimiento propio de la mismidad del Dasein que, en su momento constitutivo, no integre al otro desde su propio ámbito de relevancia, como otro que somos, en cada caso, nosotros mismos

56 Cfr. Sein und Zeit,op. cit., pp. 117-126.

57 Ibid., p. 122. 
que el otro comparezca como otro, esto es, libre para consigo mismo, respetando su propia temporalidad, y no impidiendo que éste asuma su propio ser, es decir, su temporalidad, solo de esta manera la cuestión del nosotros, o de intersubjetividad, será aclarada y puesta en su fundamento.

\subsection{Del ser-con impropio al ser-con propio: preparación del camino}

¿Es posible aprehender una experiencia en propiedad del ser-con, del "nosotros"? ¿no habíamos manifestado que no era posible captar un genuino ser-con si antes no se ha hecho temático y explícito la mismidad del Dasein? Sí, en relación con la última pregunta esto es cierto. El planteo de Heidegger al respecto es bastante claro: la estructura comunal del ser-con pre-supone partir de una experiencia genuina del sí mismo, porque, estando en el mundo, en el modo de la cotidianidad, el Dasein es el "uno mismo" 58 [man-selbst]. Ser-sí-mismo, no en la modalidad impropia otorgada por el uno, sino ser-sí-mismo propio significa la posibilidad de generar una posibilidad, en el modo de la modificación o recuperación, capaz de capacitar al Dasein para el desarrollo de una acción ejecutiva con respecto a su ser, a fin de re-tenerse en lo abierto resueltamente, mediante tal acción ejecutiva ${ }^{59}$, como modo propio de responder a lo que es. Es cierto, también, y esto complica aún más los propósitos de la meditación, que existe una palmaria prioridad de la constitución de la mismidad del Dasein en términos casi individualistas ${ }^{60}$, lo cual hace que la referencia al sercon, al "nosotros", se difumine. La pregunta pertinente de hacerse, llegados a este momento de la meditación, es la que sigue: ¿es posible hablar de un modo propio de recuperación, apropiación, por parte del Dasein, con respecto a la experiencia del ser-con? En este sentido, esta tarea estribaría en re-obtener un modo ejecutivo de acción capaz de recuperar los modos de concreción de la estructura del ser-con, a saber: "ser-junto-al-ente" [bei-sein] y "ser-uno-con-otros" [Miteinandersein], como numeradores comunes de la co-existencia ${ }^{61}$.

A partir de ahora, y como último punto de este artículo de investigación, intentaremos abrir el horizonte de los "otros" para poder pensar una propia y genuina experiencia del ser-con. Para ello, como ya hemos manifestado, nos centraremos con protagonismo en Ser y Tiempo, aunque a veces tendremos que recurrir a ciertas obras posteriores con la finalidad de aclarar lo enunciado. No obstante, el objetivo es respetar la integridad de lo abierto en Ser y Tiempo.

58 Cfr. Sein und Zeit,op. cit., p. 271.

${ }^{59} \quad$ Cfr. Infra., 5.; 5.1.; 5.2.; 5.3. Esta acción ejecutiva será denominada, más adelante, en la obra de Heidegger "resolución" [Entschlossenheit].

60 Cfr. supra., 1.

${ }^{61}$ Las investigaciones de Steven Crowell ("Conscience and Reason: Heidegger on the Grounds of Intentionality", en: Trascendental Heidegger, California, Stanford University Press, 2007, pp. 43-62 y "Subjectivity: Locating the First Person in Bein and Time", en: Inquiry 44, 2001, pp. 433-454), a pesar de no haber enfatizado en demasía la estructura del nosotros, sí, en cambio, han pensado radicalmente el papel de la "conciencia-práctica" [Gewissen], con respecto al rol que juega la noción de sí-mismo en Heidegger, en relación con el origen de la normatividad. 


\section{Fundamentación del ser-con propio: modificación (apropiación), ser-junto- al-ente, verdad de la existencia y ser-libre}

Si la tarea estribaba en re-obtener una experiencia propia del momento estructural del ser-con, debemos ser muy cautos, pues, como se ha dicho ya, Heidegger no hace un desarrollo temático de tal cuestión, apostando, al menos en Ser y Tiempo, por una resolución de carácter "decisionista", con tintes individualistas, en el sentido del quebrantamiento intransferible que produce la individuación del tender hacia la muerte como posibilidad eminente, ante el cobijo de sentido otorgado mientras estamos en el mundo hermenéuticamente hablando ${ }^{62}$. Por esta razón, deberíamos centrar nuestra atención en tres momentos que, en el punto anterior, han quedado implícitos cuando se ha intentado ubicar cómo sería el modo de captación de un ser propio relativo al ser-con, a saber: primero, se tiene que desarrollar qué significa la idea de recuperación, apropiación o modificación, que permite el vaivén entre los modos de ser impropios y propios; segundo, si es verdad que la cotidianidad es el término medio existencial, término que inicia un comienzo sin punto cero ${ }^{63}$, tendríamos que fundamentar las potencialidades de la función respectiva del serjunto-al-ente; y tercero, a fin de la renuencia del propio Heidegger a discursos modernos, subjetivistas, ha de existir una relación entre propiedad (ser propio) y "verdad de la existencia" [Wahrheit der Existenz], sobre todo para que lo desvelado por la decisión sea un conocimiento fenomenológico atestiguado en el propio

62 Esta preeminencia de la individuación, de carácter "decisionista", sobre la mismidad del Dasein y su relación con el ser-con, queda ajustada al planteamiento metódico ejercido por Heidegger a través del existenciario "ser-para(vuelto-a)-la-muerte, el cual queda enmarcado como el fenómeno "más propio" [eigenst], "irreferible" [unbezüglisch], "insuperable" [äußerst], "cierto" [gewi $\beta]$ e "incierto" [ungewi $\beta]$, en consonancia con el genuino "poder-ser" [Sein-können], de características existenciales, relativo a este ente que somos nosotros mismos, el Dasein. Resumiendo, podríamos decir: la experiencia que pone en realce el ser-para(vuelto-a)-la-muerte radica en una potenciación afectiva-comprensiva de la finitud de nuestro modo de ser, de tal modo que lo que se revela en la posibilidad que somos es una indeleble relación con la experiencia de su imposibilidad, la cual constituye su "fin(al)" [Ende]. Y esto no ha de significar que el Dasein viva muriendo, en una suerte de drama existencial sin fin (Cfr. Edwards, P. Heidegger and Death. A Critical Evaluation. Illinois: Open Court Pub, 1979), sino que este Dasein siempre ya se relaciona, en tanto poder-ser, con la posibilidad de dejar-de-ser, siendo que el fin(al) es el símbolo ineludible de su carácter, a modo de marca, "futurizo" [zukünftig]. Por tanto, este carácter "singularizante" [Vereinzelung], el cual irrumpe en la disposición afectiva de la angustia, que convoca el serpara(vuelto-a)-la-muerte, queda entramado en las derivas metódicas relativas al modo consuetudinario a través del cual el Dasein vive su existencia, siempre absorbido, entretenido, como "dentro-del" [bei] mundo, siendo, entonces, que la posibilidad más propia y genuina solo aparece singularizada, a partir de una resolución que se decide a ser conforme a lo que es, la cual, a su vez, supone una ruptura con este mecanismo de ilación hermenéutica latente en la ocupación ordinaria -recuérdese el desarrollo del "para-qué” $[U m-z u]$ perteneciente a los útiles (Cfr. Sein und Zeit, op. cit, pp. 63-113)-. Como se echará de ver a lo largo de nuestra meditación, la condición de posibilidad y de acogida de la alteridad, relativa a los otros-Dasein, radica en la posibilidad de conseguir una re-instauración significativa del sentido, entendido éste como el ámbito de previedad del venir a presencia de todo fenómeno, perteneciente a la solicitud, en el modo de la "solicitud anticipativa liberadora" [vorspringend-befriende Fürsorge]. Tal reinstauración significativa por sobre el ámbito del llamado "venir a presencia", valga decir, a la comprensión y/o inteligibilidad, presenta una clara relación con la angustia y el serpara(vuelto-a)-la-muerte como momentos posibilitadores de toda re-instauración, en la medida en que, ambos existenciarios, colocan al Dasein ante su posibilidad más plena y existencial: la nuda "existencia" [Existenz]. Ahora bien, si tanto angustia como ser-para(vuelto-a)-la-muerte son fenómenos posibilitadores, a fin de que el Dasein pueda resignificar un sentido desde su mundo-entorno y mundo-compartido, tal acto de reinstauración solo acontece como movimiento singular e individualizado a causa de que, como su consecuencia directa, la angustia y el ser-para(vuelto-a)-la-muerte solo pueden poner al Dasein ante su eminente poder-ser rompiendo los mecanismos de ilación y pertenencia hermenéutica en-el-mundo.

63 Cfr. supra., 3.1. 
existir, no un producto de la voluntad del yo, y la mismidad se libere netamente de explicaciones omnímodas derivadas de un huero idealismo y/o subjetivismo.

\subsection{El carácter de la modificación y la mismidad}

Son dos las condiciones formales características de la existencialidad del Dasein: "tener-que-ser" [zu-sein] y "ser-en-cada-caso-mío" [Jemeinigkeit]. Tanto una como la otra son propias e "irrespectivas" de ente-Dasein, no encontrándose en otra modalidad de ente. Estas condiciones formales, particularísimas del Dasein, manifiestan, a nuestro modo de ver, dos posibles atestiguaciones fenomenológicas, arraigadas en la vivencia, del ser "en propiedad" [Eigentlichkeit]. El planteo que se juega aquí es que el Dasein es, esencialmente, un ser en "estado de caída" ${ }^{4}$ [Verfallen] y esto significa que, siendo en la cotidianidad, carece de una vivencia que le ponga en camino hacia los fenómenos de la propiedad del existir. Caída significa aquí imposibilidad de atestiguación de un ser-propio. De suerte que el estado refractario de la caída, también en la modalidad del uno, es incompleto, no total. Las dos modalidades existenciales del Dasein, "tener-que-ser" y "ser-en-cada-casomío", según Heidegger, aunque soterradas, siempre están marcadas bajo el carácter del Dasein, por lo que esto significa que, sea como sea, el Dasein tiene que sentir, o padecer, su propia constitución; de nuevo: una constitución que es existencial, no intramundana ${ }^{65}$.

Ahora bien, si siendo diariamente, el Dasein es un ser caído, incapaz de autotransparentarse, algo tiene que hacerle sacudir, a fin de que la experiencia del "tenerque-ser" y "ser-en-cada-caso-mío" emerjan con toda su plenitud. Este es el sentido de la "modificación" 66 [Verwandlung], más que una turbulencia sobre la cotidianidad es su disrupción ${ }^{67}$. Tal disrupción, ya en la II Sección de Ser y Tiempo, se manifiesta en dos fenómenos muy importantes: el "ser-para(vuelto-a)-la-muerte" [sein-zumTode] y el "llamado de la conciencia" 68 [Ruf des Gewissens]. Su carácter disruptivo, de quebrantamiento para con la cotidianidad, se debe, de nuevo, a que la disrupción acontece desde el suelo de esta misma cotidianidad, no al revés. El estado de propiedad de la existencia, entonces, se divisa en base en la constitución proyectiva del Dasein, en tanto ser existente en posibilidades, que, una vez experimentada la propia insignificancia de la cotidianidad a través de la angustia, decide tomar lo que es, haciéndose cargo ejecutivamente de su respectivo ser, o sea, de su temporalidad finita (cuidado). La modificación asumida de su propio ser le revela al Dasein la necesidad de "transparencia" 69 [Durchsichtigkeit]. Y es aquí donde se pone en realce lo que denominamos "mismidad" [Selbstheit]: como el Dasein es un ser arrojado en

Cfr. Sein und Zeit, op- cit., pp. 52-59 y 175-180.

Cfr. supra., 4.2

Obsérvese que esta "modificación" existencial no tiene nada que ver con una actitud reflexiva, de corte teorético.

67 De ahí la importancia de la angustia para lograr tal atestiguación y ponernos de cara ante la posibilidad de una existencia en propiedad (Cfr. supra., nota 61).

68 Cfr. Sein und Zeit op. cit., pp. 267-301

69 Cfr. Ibíd., p. 146. La transparencia es un modo ejecutivo de comprensión, naciente del Dasein, no categorial, por el que este ente es capaz de responsabilizarse de su estado de abierto, en tanto ser en el mundo como un todo, esto es, abriéndose radicalmente por cada uno de los momentos estructurales: el "mundo-entorno" [Um-Welt], "mundo compartido" [Mit-Welt] y el "mundo de sí-mismo" [Selbst-Welt $]$, los cuales no deben ser entendidos como dimensiones estancas, sino, antes bien, como momentos co-originarios. 
posibilidades, las cuales tienen que ser articuladas y asumidas en un proyecto, este mismo Dasein tiene que elegir elegirse ${ }^{70}$. Solo cuando el Dasein elige la elección es en consonancia con respecto a sí mismo. En esto consiste la mismidad: en poder ser sí mismo a través de una decisión resuelta, la cual ha sido rehabilitada a posteriori de la ejecución de "recuperar una elección" [Nachholen einer Wahl].

Por último, nuestro modo de pensar la mismidad del Dasein ha puesto el énfasis en el "estado de resuelto" [Entschlossenheit], en tanto modo eminente de autotransparencia del Dasein, un modo eminente que desvela y pone en la verdad lo que este mismo Dasein es.

\subsection{La apertura del ser-dentro-de y la irrupción del ser-con: ser-libre y la mismidad}

¿Desde dónde se ejerce la actitud ejecutiva que comprende la transparencia del Dasein? Obviamente, desde la cotidianidad del término medio, esto es, en el modo impropio de ser del Dasein, en el momento existencial de su comprensión media, en calidad de ente que no "existe" en el mundo, sino que es "dentro-del" [bei] mundo ${ }^{71}$. Por esta razón, y atendiendo al rigor del método empleado, no puede haber un estado de resuelto que no implique la transparencia del modo de ser del ente intramundano, su desvelamiento [Entdecktheit]. Explicar pormenorizadamente su por qué, excedería los límites de este artículo de investigación ${ }^{72}$, empero, valga esta respuesta: el modo de ser del ente intramundano, en tanto útil, siempre remitía, en virtud de su constitución, al propio modo de ser del Dasein, en tanto "por-mor-de" [Worumwillen]. Es el proyecto, que sostiene en su apertura el Dasein, aquello que impone, y provee, a los entes intramundanos su propia significación.

Pero ¿qué tiene que ver esto que afirmamos con la estructura comunal del sercon? Aparentemente muy poco, pues Heidegger, sobre todo en la I Sección del tratado, con demasiada frecuencia, conecta el existenciario "ser-dentro-de" [seinbei] con la modalidad impropia de existir: el quedar absorbido, en estado de caída. En cambio, nosotros pensamos que, desde el "ser-dentro-de", hay una posibilidad de pensar el ser-con, más aún, si atendemos al estado de indiferencia que, desde el comienzo, mueve a la pregunta sobre el quién del ser-con, el quién en relación con "nosotros". Indiferencia, por lo demás, no ha de mentar una incapacidad de dar sentido, o apertura, más bien indica que, desde el modo de ser cotidiano del "ser-junto-a/dentro-de," se abren ciertos sentidos del "anunciarse" [Bekundung], en los que el ente intramundano, de manera anónima, nivelada, queda "descubierto" 73 [Entdecktheit]. O sea, hay una apertura, desde el modo de ser de la cotidianidad, que es para todo Dasein, pública; hay un anunciarse que es común, una forma de "compartir una verdad" [Sich-teilen-ein-der-Wahrheit], una orientación, promovida por la manera de "ser-uno-con-otros"74 [Miteinandersein]. Tal manera de ser en

\footnotetext{
70 Heidegger utiliza la expresión “elección de la elección” [Wählen dieser Wahl] (Sein und Zeit, op. cit., p. 268).

71 Cfr. supra., 2.2.

72 Cfr. Garrido-Periñán, J.J. "En busca del sí mismo perdido del Dasein: un diálogo entre Kafka y Heidegger en torno a la cuestión de la culpabilidad y la mismidad, en: Endoxa: Series Filósoficas 40, 2017, pp. 159-182.

73 Aunque, en Ser y Tiempo, Heidegger no explicitará en demasía este aspecto de mostración del ente intramundano, sí lo hace en la lección de 1928-1929 (Cfr. Einleitung in die Philosophie. II. Abteilung, Band 27, Frankfurt a. M.: Vittorio Klostermann, 1996, pp. 68-104). Para su desarrollo dentro del importantísimo $§ 44$ de Ser y Tiempo.

${ }^{74}$ Cfr. Olafson, F., Heidegger and the Ground of Ethics. A Study of Mitsein, Cambridge, Cambridge University
} 
comunidad, por la cual convivimos y nos relacionamos socialmente, dista de ser una concepción de carácter dialógico, ni tan siquiera, como se echa de ver, a través del tratamiento expuesto por Heidegger en la I Sección de Ser y Tiempo, para su desvelamiento, se puede apelar a una experiencia raigal de la alteridad, en tanto el otro que somos, el otro como amor y rostro ${ }^{75}$. El aparecer de los otros, como vimos, acontece circundado, casi de modo oblicuo, a través del modo de comparecencia del mundo-entorno. En algún sentido, nimio y casi imperceptible, la prefiguración de los otros se ha de sentir en el modo de aparecer de los útiles, por cuantos éstos quedan, en su constitución auto-referenciados por el modo de ser, clave para la significatividad en el mundo -la mundaneidad-, denominado "por-mor-de" [Worumwillen]. Esto explica, al menos para Heidegger, el porqué los otros aparecen como contenidos desde y con la experiencia relativa al mundo-entorno, o sea, la experiencia de la ocupación práctica ${ }^{76}$. Una alerta en el análisis se muestra ahora de modo más enfático: ¿acaso Heidegger equipara el modo de comparecencia de los útiles con el modo de comparecencia de los otros? ¿Afirma, entonces, Heidegger que, en lo relativo al aparecer fenoménico, el otro aparece como útil? Por más que pudiera sorprender, en parte, y según las atenencias metódicas adoptadas, tendríamos que responder con un claro sí; pero, por otra, es menester señalar que al aparecer del otro le pertenece una singularidad irreductible a cualquier modo relativo a los útiles. Grosso modo, la ambigüedad de tal respuesta se debe a la determinación que supone la adopción de un método, como el fenomenológico, el cual sirve de guía conductora del opus magnum heideggeriano, que incapacita pensar al Dasein en tanto substancia, género, o a la manera de unos "autoengaños egocéntricos" [egozentische Selbsttäuschungen], pues siempre ya el Dasein, no siendo nunca constituido al modo de la Vorhandenheit, es co-originario con lo relacionado mismo, sus relatas. Por esta razón, decimos que los otros aparecen coligados a los útiles, ya que comparecen estando en el mundo, "dentro-de" [bei], a través de la ocupación, y no, más bien, como desligados de aquella instancia que en medianía somos: una actividad de orden práctico. Por tanto, que el otro aparezca desde la modalidad de la ocupación, relativa al orden de comparecencia del ente intramundano, significa, en parte, que el otro, desde su constitución, se muestra adquiriendo miméticamente los caracteres específicos del ente intramundano. Ahora bien, en nuestra respuesta también se ha determinado un no rotundo: a los otros, en virtud de su constitución existencial, -por más que el aspecto "sigularizante" propulsado por una angustia que se sabe mortal sea eminente- le pertenece un modo de ser absolutamente refractario ante cualquier configuración categorial, cuyos resultados provoquen una cierta reificación o instrumentalidad para con los otros, pues, siempre ya, los otros, los cuales son otros-Dasein, no están surcados por la "reemplazibilidad"77 [Ersetzbarkeit], es decir, y a las claras:

Press, 1999, pp. 15-39. Aunque, desde una diferente línea interpretativa, desarrolla la relación de "ser en la verdad" y el "ser-con". Mencionar, en relación con la temática, el sobresaliente trabajo del Profesor Alejandro Vigo (Arqueología y aleteiología y otros estudios heideggerianos, Buenos Aires: Biblios, 2008, pp. 259-290), donde se intenta ubicar la constitución del "nosotros" en la obra de Heidegger, en especial atención al Curso del Semestre de Verano impartido por Heidegger en 1934 (Cfr. Logik als die Frage nach dem Wesem der Sprache, op. cit.).

75 Cfr. Bernasconi, R. The Provocation of Levinas. Rethinking the Other. Lodon/New York: Routledge, 1988; Levinas, E. Totalidad e infinito. Ensayo sobre la exterioridad. Traducción de A. Pitor. Salamanca: Síguemem 1999; Theunissen, M. Der Anderen Studien zur Sozialontologie der Gegenwart, op. cit.

76 Sein und Zeit, op. cit, pp. 239: "Se es lo que se hace(practica)" [Man ist das, was man betreibt].

77 Cfr. Ibid., pp. 117-125 
son irreemplazables. Esto nos convoca a pensar, por lo demás, que al igual que el ser-para(vuelto-a)-la-muerte realza una posibilidad "irreferible" [unbezüglich], los otros, aunque de manera menos obvia y menos marcada por un estado afectivo disruptivo, también aparecen siendo "irreferibles", por cuanto son irreemplazables. ¿Quién puede sustituir a un amigo muerto?

Pensamos que Heidegger no es ciego para ante esta cuestión, el análisis desarrollado sobre los $\S \S 25-27$ da buena cuenta de ello, a pesar, como decimos, que las atenencias de adopción del método fenomenológico, el cual demanda "atestiguaciones" [Bezeugungen] marcadas en la experiencia, pudieran provocar un nimio tratamiento instrumental y reductivo por sobre el modo de aparecer de los otros. El carácter de irreemplazabilidad ha de servir como indicación que nos haga pensar que los otros, que somos nosotros mismos, no aparecen, tan solo, dentro-del mundo, sino como teniendo mundo, esto es, soportándolo, cargando con una temporalidad finita, como modo de temporalidad que cuida, etc. Los otros, en concreto, el otro-Dasein está, por ende, atravesado por los existenciarios que preservan la existencialidad y la facticidad: el tener-que-ser y el ser-en-cada-caso-mío. Solo de este modo, pensamos, es posible explicar una estructura existencial y ontológica denominada "ser-con" [Mit-sein], en tanto estructura que posibilita, configurándola, toda posible acción de comunicación y co-existencia [Mitdasein]. Que el otro, entonces, enmarcado a través de la experiencia del ser-con, sea ontológico ha de significar: a) que el otro es "también y ahí con" [auch und mit da]; b) que su constitución es existencial, no categorial, al modo de la Vorhandenheit; c) y en último lugar, que el "también" [auch] no ha de presentarse como una suma de individuos como si cada uno estuviera en su mundo, sino que tal "también" ha de mentar la singladura de un mundo-compartido [Mit-Welt], el cual es desde el origen, siempre ya. Ahora se puede entender una expresión ocupada por Heidegger, aparentemente desconcertante: "igualdad de ser" solamente el mundo-entorno es, desde origen, compartido, sino que el otro, en tanto experiencia que funda la alteridad, es constitutivo a todo Dasein. ¿Cómo, entonces, se "singulariza" este modo de comparecer relativo a los otros, siendo que toda forma de considerarlos al modo de los útiles, provoca una reducción y un constreñimiento en su aparecer? Como ya hemos apuntado ${ }^{79}$, este modo de comparecencia singular, en relación con los útiles, es tematizado a través de la "solicitud" [Fürsorge]. Pues bien, la solicitud, la cual es una estructura que constituye la condición de posibilidad de todo acto con los otros, cuando se da propiamente, esto es, cuando deviene autorreferencial, permitiendo la apertura del Dasein en sí-mismo, viene rasgada por un carácter "anticipativo liberador" [verspringend-befreienden], el cual tiene lugar como acto ligado a la misma anticipación existencial del Dasein, en tanto tenerque-ser y ser-en-cada-caso-mío. Lo que se anticipa, desde esta modalidad excelsa de solicitud es un "salto anticipativo frente al otro" [Vorausspringen dem Anderen gegenüber] bajo la finalidad ineluctable de devolverle al otro lo que está siempre ya a su cuidado como lo que, justamente, está a su cuidado, sin más. Y esta actividad de re-significación, signada por Heidegger como un salto, es necesaria porque la

\footnotetext{
78 Ibíd., p. 118: "El con- es una posibilidad del Dasein, el también significa la igualdad de ser como un ser-enel-mundo ocupándose circunspectivamente de él” [Das »Mit« ist ein Daseinsmäßiges, das »Auch« meint die Gleichheit des Seins als umsichtig-besorgendes In-der-Welt- sein].

79 Cfr. supra., 4.1.
} 
convivencia y la coexistencia están, a su modo, niveladas, donde la figura de la alteridad, la mayoría de las veces, es pensada y abierta como un medio, desde un rasgo instrumental y, otras veces, en cambio, como Heidegger suele tematizar, aparece como modalidad relativa al "estado de caída" [Verfallen], donde el Dasein es el "uno-mismo" [man-selbst]. La solicitud anticipativo-liberadora lo que busca es, por tanto, un "dejar/poner en libertad" [freigeben/Freigaben] al otro en cuanto otro. En buena medida, el fin de este tipo de solicitud eminente, partiendo de una igualdad de corte pre-ontológico ${ }^{80}$, radica en provocar una liberación en el irrumpir a presencia de los otros en cuanto otros, pero para ello, como se ha dejado ver, resulta necesario un movimiento de anticipación, rayano con lo que Heidegger llamará en la II Sección "resolución” [Entschlossenheit], a través de la cual el Dasein, desde un modo individual y "singularizante", re-instituye el ámbito de aparecer y de sentido de los otros, permitiendo que el otro acontezca como otro que se cuida.

\subsection{La verdad de la existencia y la posibilidad de un ser-con propio: la libertad para/del otro}

A pesar de que hayamos realzado la modalidad relativa al "ser-dentro-de", específico del ente intramundano, en su papel constituyente, estructural, a la hora de explicar el "estado de resuelto" del Dasein, sin embargo, desde la modalidad respectiva al "serdentro-de", es imposible dar cobertura al cambio existencial que se produce entre las modalidades de impropiedad y propiedad. Y ello a razón de la "ambivalencia" [Zweideutigkeit] peculiar del Dasein, un ente que está en la verdad y en la no-verdad de su existir ${ }^{81}$. La ambivalencia es de tal grado que la posibilidad de ser en propiedad, promovido por una decisión conforme a aceptar la temporalidad que constituye su existencia, no tiene el carácter de cosa, no es un "objeto" [Gegenstand]. Ahora bien, seríamos poco cautos si entendemos la ambivalencia del Dasein como un aspecto negativo del mismo. A nuestro juicio, la ambivalencia, la cual es connatural al carácter proyectivo del existir, permite el re-surgimiento de la posibilidad de un modo propio de ser. Este modo propio de ser, para con esta meditación, tiene que ver con rehabilitar su posibilidad en relación con la estructura del ser-con. ¿Será posible? Pensamos que sí. Ya vimos que, desde la modalidad de acceso a los otros denominada "solicitud" [Fürsorge], había un modo propio de acceso al otro que lo signamos bajo expresiones tales como "solicitud anticipativa liberadora", "nointervencionista" "ni sustitutiva" 82 , etc. Todas estas expresiones tienen en común en que son acciones ejecutivas del Dasein, de re-tención, donde el "otro" es integrado como Dasein al que no se le puede usurpar su "irrespectiva" carga de ser, su genuina responsabilidad.

80 Conviene, aunque brevemente, matizar el porqué tal experiencia es pre-ontológica y no ontológica. La experiencia ontológica, desde el planteamiento desplegado en Ser y Tiempo, nunca puede ser entendida en términos de igualdad, en virtud de la tematización realizada sobre la propiedad e impropiedad de la existencia, siendo que el Dasein propio, como modalidad relativa a su mismidad, es aquel que se resuelve a ser lo que es, aceptando su finitud radical. En este sentido restringido, por cuanto ontológico, la igualdad nunca es un término que pudiera ser aplicable y, por ende, que sirviera de nexo explicativo de cara a dar cuenta de la propiedad de la existencia. En cambio, la igualdad sí es pre-ontológica porque queda tematizada como aquello que "es", pero, por su constitución existencial, en el orden predicativo y reflexivo, no queda tematizada. Por esta razón podríamos decir que la igualdad de ser es "no-extraña" [nicht-fremd].

81 Que el Dasein esté en la no-verdad y verdad significa que continuamente se mueve entre el estado de caída y una exigencia de (auto)comprensión en armonía con su propia temporalidad.

82 Cfr. supra., 4.1. 
¿Se podrá, entonces, rehabilitar una experiencia propia del ser-con, desde tal situación de ambivalencia, donde prima el estado de "pérdida de sín" [Selbstverlorenheit] propia de la cotidianidad, dejando al margen las afirmaciones heideggerianas porteriores en torno al "pueblo" [Volk]? Pensamos que sí, pero tenemos que ser conscientes de que, desde la perspectiva heideggeriana, la respuesta debe ser limitada, a razón de que, como hemos manifestado con anterioridad ${ }^{83}$, para con el estado de propiedad, y desde Ser y Tiempo, obtienen primacía las modalidades "individuales" de existencia. Más aún, como también se manifestó ${ }^{84}$, no puede haber un ser-con en propiedad que no presuponga una asunción del Dasein con respecto a sí, con su mismidad. No obstante, la posibilidad de un estado propio del existir se comprendió como una modalidad de "modificación" del modo cotidiano de ser-enel-mundo, apelando al carácter preeminente de la apertura ejecutiva que lleva tras de sí la decisión. El estado de resuelto advendría, desde el proyecto-arrojado que constituye al Dasein, como colofón de una decisión decidida a ser lo que es. Esta decisión, fundamental, no tendría un carácter teórico, propio de la actitud teorética y reflexiva, sino que, más bien, advendría como un momento ejecutivo, de carácter temporal, que tiene que ver con un "adelantarse a la posibilidad" [Vorlaufen in die Möglichkeit]. Ahora bien, tal decisión supone para Heidegger un compromiso por y para lo decidido. La decisión que toma el Dasein, desde el proyecto arrojado de mundo que es, se hace siempre desde el trasfondo del "haber-llegado-a-ser" 85 [Gewordensein], constitutivo de la facticidad. Esta facticidad se le revela al Dasein como fondo indisponible desde su propio proyecto. El ser-con, como existenciario que soporta cualquier modalidad de convivencia, aparece co-ligado a la facticidad y el haber-llegado-a-ser, en un primer momento, revestido en la modalidad de comprensión impropia, por cuanto es entendido como "el uno", la "Historiografia", etc., pero, en un segundo momento, desde la genuina decisión que posibilita el estado de apertura, abierto en la posibilidad de su concreción propia. Dicho de otro modo, la "verdad de la existencia", que constituye el corolario de las consecuencias ejecutivastemporales proporcionadas por el estado de apertura, permite que el Dasein pueda re-tornar al fondo indisponible del haber-llegado-a-ser y la facticidad, a fin de que el otro pueda aparecer, precisamente, como otro-Dasein. Solo así es posible generar una solicitud no intervencionista para con el otro: retornarnos al ser-con desde la impronta ejecutiva promovida por el estado de resuelto, en la modalidad de "ser lo que se es", cuando el Dasein es conforme a su mismidad. De este modo, el fondo comunal del ser-con, y el "nosotros" que le acompaña, ya no aparecería en el modo de la indiferencia, sino en el modo de la concreción de su genuina historicidad ${ }^{86}$.

La verdad de la existencia, por lo demás, permite la posibilidad existencial de la solicitud anticipativo-liberadora como la más alta modalidad de libertad por la que el otro deviene "otro" siendo libre para lo que es. Por tanto, la mismidad de la que hablamos, como acto de apertura de sí del Dasein, a partir de la cual este Dasein queda abierto qua Dasein, siempre ha de prevalecer en el "comportarse"

\footnotetext{
Cfr. supra., 1.

Cfr. supra., 3.

85 El rol que juega la facticidad en la mismidad es analizado por nosotros ( $C f r$. "La experiencia de la religiosidad: caminos fenomenológicos en busca de la mismidad del Dasein. Heidegger y la fenomenología de la religión”, op. cit., pp. 533-556) al socaire del tratamiento heideggeriano en torno a la experiencia temporal de las primitivas comunidades cristianas abiertas en las Epístolas paulinas.

86 Cfr. Sein und Zeit, op. cit., $\S \S 72-77$.
} 
[sich-verhalten] en el mundo que es este ente que somos nosotros mismos. Solo de este modo, siendo sí-mismo, es posible hablar de libertad y, en consecuencia, es posible la re-institución de sentido por la que el otro aparece siendo otro. Esta es la más eximia forma de libertad, o sea, la libertad para/del otro.

\section{Referencias bibliográficas}

Bernasconi, R. The Provocation of Levinas. Rethinking the Other. Lodon/New York: Routledge, 1988.

Blust, F-K. Selbstheit und Zeitlichkeit. Heideggers neuer Denkansatz Seinsbestimmung des Ich. Würzburg: Königshausen \& Neumann, 1987.

Caygill, H. A Kant dictionary. Oxford-Massachusetts: Blackwell, 2000.

Crowell, S. "Conscience and Reason: Heidegger on the Grounds of Intentionality", en: Trascendental Heidegger. California: Stanford University Press, 2007, pp. 43-62. Crowell, S. "Subjectivity: Locating the First Person in Bein and Time", en: Inquiry 44, 2001, pp. 433-454.

Edwards, P. Heidegger and Death. A Critical Evaluation. Illinois: Open Court Pub, 1979.

Foucault, M. L’ Herméneutique du Sujet. Paris: Gallimard, 2001.

Fräntzki, E. Die Kehre. Heideggers Schrift Vom Wesen der Wahrheit: Urfassungen und Druckfassungen. Pfaffenweiler: Centaurus-Verlagsgesellschaft, 1985.

Garrido-Periñán, J.J. "Caminos y esbozos para una apertura fenomenológica del horizonte mismidad desde la constitución ontológica del mundo en Ser y Tiempo" [Aceptado para su publicación], en: TRANS/FORM/AÇAO: Revista de Filosofia 42, 2019.

Garrido-Periñán, J.J. Horizontes fenomenológicos de la espacialidad en Ser y Tiempo: la relevancia del ser-en como vía de acceso a la mismidad del Dasein", en: Eidos: Revista de Filosofia de la Universidad del Norte 29, 2018, pp. 150-174.

Garrido-Periññan, J.J. "Fenomenología del ser-en: ciencia originaria de la vida y hábitat del Dasein. En búsqueda de la vivencia inmediata de la vida", en: Revista da Faculdade de Letras da Universidade do Porto 33, 2017, pp. 139-160.

Garrido-Periñán, J.J. "En busca del sí mismo perdido del Dasein: un diálogo entre Kafka y Heidegger en torno a la cuestión de la culpabilidad y la mismidad, en: Endoxa: Series Filósoficas 40, 2017, pp. 159-182.

Garrido-Perinán, J.J. "Ser-en-el-cuerpo: tentativas para un esclarecimiento sobre cómo aparece un cuerpo. En y mundo", en: Daimon: Revista Internacional de Filosofia. Suplemento 5, 2017, pp. 63-73.

Garrido-Periñán, J.J. "La experiencia de la religiosidad: caminos fenomenológicos en busca de la mismidad del Dasein. Heidegger y la fenomenología de la religión", en: Revista Portuguesa de Filosofía 73, 2017, pp. 533-556

Garrido-Periñán, J.J. "Crítica de la razón del comenzar: esbozos hacia una filosofía del nacimiento", en: Eikasia: Revista Internacional de Filosofia 44, 2012, pp. 99-112.

Heidegger, M. Einführung in die phänomenologische Forschung. II. Abteilung, Band 17, Frankfurt a. M.: Vittorio Klostermann, 2006.

Heidegger, M. Geschichte der Philosophie von Thomas von Aquin bis Kant, II. Abteilung, Band 23, Frankfurt a. M.: Vittorio Klostermann, 2006.

Heidegger, M. Phänomenologische Interpretation ausgewählter Abhandlungen des Aristoteles zu Ontologie und Logik. Gesamtausgabe, II. Abteilung, Band 62, Frankfurt a. M.: Vittorio Klostermann, 2005. 
Heidegger, M. Grundbegriffe der aristotelischen Philosophie, II. Abteilung, Band 18, Frankfurt a. M: Vittorio Klostermann, 2002.

Heidegger, M. Sein und Zeit. Tübingen: Max Niemeyer, 2002.

Heidegger, M. Einleitung in die Philosophie, II. Abteilung, Band 27, Frankfurt a. M.: Vittorio Klostremann, 1996.

Heidegger, M. Phänomenologie des Religiösen Lebens. II. Abteilung, Band 60, Frankfurt a. M.: Vittorio Klostermann. 1995.

Heidegger, M. Platon: Sophistes. II. Abteilung, Band 19, Frankfurt a. M.: Vittorio Klostermann, 1992.

Heidegger, M. Kant und das Probleme der Metaphysik, I. Abteilung, Band 3, Frankfurt a. M.: Vittorio Klostermann, 1991.

Heidegger, M. Die Grundprobleme der Phänomenologie, II. Abteilung, Band 24, Frankfurt a. M. Vittorio Klostermann, 1989.

Heidegger, M. Phänomenologische Interpretationen zu Aristoteles. Einführung in die phänomenologische Forschung. II. Abteilung, Band 61, Frankfurt a. M.: Vittorio Klostermann, 1985.

Heidegger, M. Ontologie (Hermeneutik der Factizität). II Abteilung, Band 63, Frankfurt a. M.: Vittorio Klostermann, 1988.

Heidegger, M. Prolegomena zur Geschichte des Zeitbegriffs. II. Abteilung, Band 20, Frankfurt a. M.: Vittorio Klostermann, 1979.

Heidegger, M. Logik. Die Frage nach der Wahrheit, II. Abteilung, Band 21, Frankfurt a. M.: Vittorio Klostermann, 1976.

Heidegger, M. Wegmarken. Gesamtausgabe, I. Abteilung, Band 9, Frankfurt a. M.: Vittorio Klostermann, 1976.

Heidegger, M. Der Grundprobleme der Phänomenologie. II Abteilung, Band 24, Frankfurt a. M.: Vittorio Klostermann, 1975.

Hermann, F-W. Hermeneutik und Reflexion. Der Begriff der Phänomenologie des seinsgeschichtlichen Denkens. Frankfurt a. M.: Vittorio Klostermann, 2000.

Hermann, F-W. Wege ins Ereignis: zu Heideggers Beiträgen zur Philosophie, Frankfurt a. M.: Vittorio Klostermann, 1994

Husserl, E. Cartesianische Meditationen und Pariser Vorträge. Husserliana I, Den Haag: Martinus Nijhoff, 1973

Kant, I., Metaphysische Anfangsgründe der Tugendlehre, Metaphysik der Sitten, Zweiter Teil, Hamburg, Felix Meiner Verlag, 2017.

Kant, I. Crítica de la razón pura. Trad. Pedro Ribas. Taurus: Madrid, 2005.

Kant, I. Opus postumun. Trad. Eckart Förster y Michael Rosen. New York: Cambridge University Press, 1993.

Kant, I. Kritik der reinen Vernunft. Hamburg: Felix Meiner Verlag, 1956.

Kisiel, Th. The Genesis of Heidegger Being and Time. California: University of California Press, 1995.

Levinas, E. Totalidad e infinito. Ensayo sobre la exterioridad. Traducción de A. Pitor. Salamanca: Síguemem 1999.

Merker, B. Selbsttäuschung und Selbsterkenntnis. Zu Heideggers Transformation der Phänomenologie Husserls. Frankfurt a. M.: Suhrkamp Verlag, 1988.

Moreno, C. "Una suerte de calma hechizada. Praxis de extrañamiento y trascendencia poética (Paseando por el rastro con Gómez de la Serna), en: Contrastes: Revista Internacional de Filosofía 3, vol. 21., 2016, pp. 74-94. 
Olafson, F. Heidegger and the Ground of Ethics. A Study of Mitsein. Cambridge: Cambridge University Press, 1999.

Overenget, E. Seeing the Self. Heidegger on Subjectivity. Dordrecht-Boston-London: Springer, 1998.

Richardson, W-J. Heidegger, Through Phenomenology to Thought. The Hague: Martinus Nijhoff, 1963.

Riccoeur, P. Soi-même comme un autre. París: Seuil, 1990.

Rodríguez, R. Del sujeto y la verdad. Madrid: Síntesis, 2015.

Rodríguez, R. La transformación hermenéutica de la fenomenología: una interpretación de la obra de Heidegger. Madrid: Tecnos, 1997.

Rosales, A. "Zum Problem der Kehre im Denken Heideggers", en: Zeitschrift für philosophische Forschung 38, 1984, pp. 241-262.

Segura-Peraita, C. Hermenéutica de la vida humana. En torno al Informe Natorp de Martin Heidegger. Madrid: Trotta, 2002.

Theunissen, M. Der Andere. Studien zur Socialontologie der Gegenwart. Berlin-New York: Walter de Gruyter \& Co, 1964.

Vigo, A. "La atestiguación, en el modo de ser del Dasein, de un poder-ser propio y en estado de resuelto", en: R. Rodríguez (ed.), Ser y Tiempo de Martin Heidegger. Un comentario fenomenológico, Tecnos: Madrid, 2016, pp. 167-218.

Vigo, A. "Identidad, decisión y verdad. Heidegger, en torno a la constitución del nosotros", en: Arqueología y aleteiología y otros estudios heideggerianos, Buenos Aires, Biblios, 2008, pp. 259-290. 